Florida International University FIU Digital Commons

FIU Electronic Theses and Dissertations

University Graduate School

7-24-1997

\title{
Substructuring in four populations of African descent
}

Margarita Teresa Almeida

Florida International University

DOI: $10.25148 /$ etd.FI13101597

Follow this and additional works at: https://digitalcommons.fiu.edu/etd

Part of the Biology Commons

\section{Recommended Citation}

Almeida, Margarita Teresa, "Substructuring in four populations of African descent" (1997). FIU Electronic Theses and Dissertations. 1073.

https://digitalcommons.fiu.edu/etd/1073

This work is brought to you for free and open access by the University Graduate School at FIU Digital Commons. It has been accepted for inclusion in FIU Electronic Theses and Dissertations by an authorized administrator of FIU Digital Commons. For more information, please contact dcc@fiu.edu. 
FLORIDA INTERNATIONAL UNIVERSITY

Miami, Florida

SUBSTRUCTURING IN FOUR POPULATIONS OF AFRICAN DESCENT

A thesis submitted in partial satisfaction of the requirements for the degree of

MASTER OF SCIENCE

IN

BIOLOGY

by

Margarita Teresa Almeida

1997

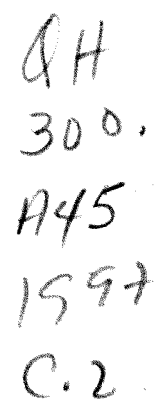


To: Dean Arthur W. Herriott College of Arts and Science

This thesis, written by Margarita Teresa Almeida, and entitled Substructuring in Four Populations of African Descent, having been approved in respect to style and intellectual content, is referred to you for judgement.

We have read this thesis and recommend that it be approved.

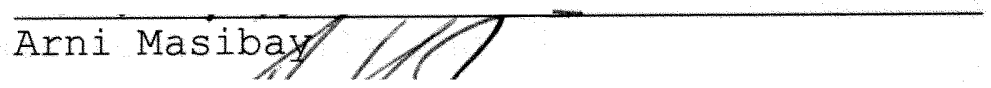

Rene/F\% Horrerg

case K. okubo

Martin L. Tracey, Major Professor

Date of Defense: July 24,1997

The thesis of Margarita Teresa Almeida is approved.

Dean Arthur W\% Herriott

Collgge of Arts and Science

Dr. Richard L. Calmpbeli

Dean of Graduate Studies

Florida International University, 1997 
I dedicate this thesis to my family and clinton A. El-Ramey for all their support. 


\section{ACKNOWLEDGEMENTS}

I would like to thank my major professor, Dr. Martin

L.Tracey for all his time and patience in explaining all the statistics envolved. I would also like to thank, Dr. Arni Masibay for his technical support and help when problems arose. A special thanks to everyone at the Broward Sheriff's Office Crime Lab, DNA section, especially Dr. George Duncan for all his input and advice. 


\section{ABSTRACT OF THE THESIS}

SUBSTRUCTURING IN FOUR POPULATIONS OF AFRICAN DESCENT By

Margarita T. Almeida

Florida International University, 1997

$$
\text { Miami, Florida }
$$

Professor Martin L. Tracey, Major Professor

When a suspect's DNA profile is admitted into court as a match to evidence the probability of the perpetrator being another individual must be calculated from database allele frequencies. The two methods used for this calculation are phenotypic frequency and likelihood ratio. Neither of these calculations takes into account substructuring within populations. In these substructured populations the frequency of homozygotes increases and that of heterozygotes usually decreases. The departure from HardyWeinberg expectation in a sample population can be estimated using Sewall Wright's $F_{S T}$ statistic. $F_{S T}$ values were calculated in four populations of African descent by comparing allele frequencies at three short tandem repeat loci. This was done by amplifying the three loci in each sample using the Polymerase Chain Reaction and separating these fragments using polyacrylamide gel electrophoresis. 
The gels were then silver stained and autoradiograms taken, from which allele frequencies were estimated. $F_{S T}$ values averaged $0.007 \pm 0.005$ within populations of African descent and $0.02 \pm 0.01$ between white and black populations. 
I. INTRODUCTION 1

II. MATERIALS \& METHODS 4

$\begin{array}{ll}\text { III. RESULTS } & 20\end{array}$

IV. DISCUSSION 31

V. REFERENCES 35

VI. APPENDICES 38

REAGENTS USED 38

YIELD GEL RESULTS 44

FIGURE 1:YIELD GEL PHOTOGRAPH 49

SLOT BLOT VALUES 50

FIGURE 2:SLOT BLOT PHOTOGRAPH 53

FIGURE 3:PRODUCTGEL PHOTOGRAPH 54

TABLE 1: CTT TM INFORMATION $_{\text {TM }}$

ALLELE FREQUENCIES FOR THREE LOCI 56

FIGURE 4:ANALYTICAL GEL PHOTOGRAPH 57

$F_{S T}$ CALCULATIONS 59

TABLE 2: G TEST VALUES FOR THREE LOCI 89

TABLE 3: $\chi^{2}$ VALUES FOR THREE LOCI 90

TABLE 4: T TEST VALUES BETWEEN BROWARD
WHITES \& ADP

TABLE 5: T TEST VALUES BETWEEN 92 


\section{INTRODUCTION}

When a suspect's DNA profile is admitted into court as evidence the probability of the perpetrator being another individual must be calculated from database allele frequencies. There are two methods commonly used for this calculation. One method includes determining the phenotypic frequency. That is the probability of the phenotypic frequency is calculated from database allele frequencies for that population. The second method includes the determination of the likelihood ratio. Which is the ratio of the probability of a match if the DNA in the evidence sample and that from the suspect came from the same person to the probability of a match if it came from a different person. The same information is given in the calculations of phenotypic frequency and likelihood ratio because they are reciprocal $(1-5)$.

Neither of these calculations takes into account substructuring of the populations. Since the suspect belongs to a subpopulation, it is possible to calculate phenotypic frequencies by assuming that substructuring is present. This would give a different calculation of phenotypic frequency or likelihood ratio(1,3-6). Inbreeding 
is defined as the mating of two persons who are more closely related than if they were chosen at random. This can occur when marriage between close relatives takes place, such as, second cousin marriages. Alternatively it can occur because the entire population is divided into subpopulations showing positive assortive mating. Both forms of inbreeding cause an increase in the frequency of homozygotes and usually a decrease in the frequency of heterozygotes. The first type of inbreeding is denoted as $F_{\text {IS }}$ or $F_{\text {IT. }}$ They measure the decrease in heterozygosity of an individual within its subpopulation and the decrease in heterozygosity of an individual relative to the whole population, respectively. The second, the degree of relatedness in a subpopulation can be estimated by using Sewall Wright's $F_{S T}$ statistic. $F_{S T}$ measures the degree of excess homozygosity within a subpopulation in comparison with the total population $(7,8)$. This population subdivision causes an increase in the frequency of homozygous genotypes and a decrease in the frequency of heterozygous genotypes $(1,7,8)$.

FST values were calculated for all possible comparisons for 60 samples of each of the following populations: Broward 
whites, Broward blacks, Bahamians, Jamaicans, and Trinidadians. The average $F_{S T}$ value was found to equal 0.01 for these populations. This was done by determining the allele frequencies for three short tandem repeat loci for each sample in the populations used.

Short tandem repeats (STR's) are polymorphic loci consisting of $3-7$ base pair repeats that occur in tandem in varying frequencies in eukaryotic organisms. The three loci used were HUMCSF1PO, HUMTPOX, and HUMTHO1. HUMCSF1PO (CSF1PO) is located on chromosome five at the site for colony stimulating factor-1 receptor gene and has a repeat sequence of $5^{\prime}-A G A T-3^{\prime}$ that occurs between 6-15 times, in most populations. HUMTPOX (TPOX) is located on chromosome two at the site of the human thyroid peroxidase gene and has a repeat sequence of $5^{\prime}-\mathrm{AATG}-3^{\prime}$ that occurs between 613 times. HUMTHO1 (THO1) is located on chromosome eleven at the site for the human tyrosine hydroxylase gene and has a repeat sequence of $5^{\prime}-\mathrm{AATG}-3^{\prime}$ that is repeated between 5-11 times. There is a common mutation in the THO1 STR that is not a true STR but since it so common it is used as an additional allele for identification purposes. This 9.3 
allele repeat is, in fact, a 10 allele repeat with a base pair deletion $(9,10,11)$.

These three STR loci were amplified using the polymerase chain reaction (PCR) separated by electrophoresis in a denaturing polyacrylamide gel. The alleles were then read from an autoradiogram of the silver stained gel.

\section{II.MATERIALS AND METHODS}

DNA EXTRACTION

1. Cut a $.5 \mathrm{~cm} X .5 \mathrm{~cm}$ square of stain and place in a 1.5 ml microcentrifuge tube.

2. Add $400 \mu l$ stain extraction buffer and $10 \mu l$ proteinase K. Mix and spin in Eppendorf microcentrifuge $5415 \mathrm{C}$ for 1 minute at $10,000 \mathrm{rpm}$ to force stain to bottom of the tube.

3. Incubate at $56^{\circ} \mathrm{C}$ overnight.

4. Spin for 2 seconds to force condensation to bottom of tube.

5. Punch 3 holes in lid of tube in triangle formation, open tube and place cutting on lid and close and spin for 5 minutes at $10,000 \mathrm{rpm}$.

6. Remove lid and discard in biohazzardous container.

* Following two steps must be conducted in fume hood* 
7. Add $500 \mu l$ of phenol/chloroform/isoamyl alcohol, place new lid on tube, shake well by hand to achieve a milky emulsion in the tube, spin for 2 minutes at $10,000 \mathrm{rpm}$.

8. Transfer the aqueous phase (top layer) to another $1.5 \mathrm{ml}$ microcentrifuge tube.

9. To the aqueous phase add $1.0 \mathrm{ml}$ of cold absolute alcohol.

10. Mix by hand and place in $-20{ }^{\circ} \mathrm{C}$ freezer for 30 minutes. 11. Spin tube for 20 minutes at $10,000 \mathrm{rpm}$.

12. Remove absolute alcohol by slow decantation.

13. Add $1 \mathrm{ml}$ of room temperature $70 \%$ alcohol.

14. Spin for 5 minutes at 10,000 rpm.

15. Remove $70 \%$ alcohol by slow decantation being careful not to disturb pellet.

16. Place tube in Savant Speed-vac, to remove remaining alcohol, for approximately 20 minutes.

17. Resolubilize the DNA in $36 \mu \mathrm{l}$ of $\mathrm{TE}$ overnight in $56^{\circ} \mathrm{C}$ incubator.

or after step \#7 continued with following protocol

8. Add aqueous layer to Microcon-100 (Amicon \#42413) and bring up volume to top line with TE.

9. Spin in centrifuge at $5100 \mathrm{rpm}$ for 10 minutes. 
10. Dispense TE from reservoir and add more TE to filter to top line.

11. Spin in centrifuge at $5100 \mathrm{rpm}$ for another 10 minutes. 12. Dispense entire reservoir, invert filter into sample reservoir and spin at $5100 \mathrm{rpm}$ for 2 minutes.

13. Add approximately $20 \mu l$ of ultrapure water to DNA pellet.

14. Vortex briefly then centrifuge at $5100 \mathrm{rpm}$ for 1 second. Can immediately go to yield gel.

YEILD GEL

1. Measure $1 \mathrm{gm}$ of ultrapure agarose in $250 \mathrm{ml}$ Erlenmeyer flask and $100 \mathrm{ml}$ of $\mathrm{TAE}$ and microwave for 3 minutes or until agarose dissolves.

2. Add $10 \mu l$ of ethidium bromide and let gel mix cool to 56 ${ }^{\circ} \mathrm{C}$.

3. Pour in $12 \times 15 \mathrm{~cm}$ gel tray and place gel comb in place and let stand 30 minutes.

4. Place gel in gel tank and add TAE buffer so that gel is covered.

5. Add $6 \mu \mathrm{l}$ of each of the following DNA standards to the first six wells: $500 \mathrm{ng}, 250 \mathrm{ng}, 125 \mathrm{ng}, 63 \mathrm{ng}, 31 \mathrm{ng}$, and $15 \mathrm{ng}$. 
6. Add $4 \mu \mathrm{I}$ of sample DNA and $2 \mu \mathrm{l}$ of loading solution in the following wells.

7. Set voltage at 200 volts on power supply and run for approximately 20 minutes or till loading solution has run 1-2 $\mathrm{cm}$ from the origin.

8. Turn off power supply and remove gel from tank and view on Fotodyne ultraviolet light transluminator.

9. Photograph the gel with Polaroid \#667 $8.5 \times 10.8 \mathrm{~cm}$ film. With red filter in place being careful not to expose eyes to UV light.

10. Using standards quantitate amount of DNA in sample.

11. Can go immediately to Amplification of sample or further quantitate using the slot Blot procedure

SLOT BLOT

1. Determine number of samples to be blotted including the following DNA standards

(10 ng , $5 \mathrm{ng}, 2.5 \mathrm{ng}, 1.25 \mathrm{ng}, .625 \mathrm{ng}, .312 \mathrm{ng}, .156$ ng) .

2. Add $150 \mu l$ of spotting solution for each sample and standard to microtiter plate.

3. Add $5 \mu$ l of each standard in its corresponding well. 
4. Using yield gel quantitation add approximately $5 \mathrm{ng}$ of sample DNA to its corresponding well.

5. Obtain $8 \times 11 \mathrm{~cm}$ Biodyne B membrane and cut a notch on the bottom right corner for orientation and soak in wetting solution for 1 minute.

6. Place membrane on gasket of the Gibco BRL Convertible Filtration Manifold System and place top plate over membrane.

7. Turn on vacuum source, turn off sample vacuum and turn on clamp vacuum. Push down to insure tight seal.

8. Pipette $155 \mu l$ of sample and spotting solution mixture, as well as standards in the appropriate slots using a different pipette for each sample.

9. When all sample have been blotted turn on sample vacuum and leave on till all samples have been drawn through membrane and each slot has a uniform blue band. 10. Turn off clamp vacuum then vacuum source.

11. Disassemble slot blot apparatus and remove membrane. 12. Bake membrane between blotting paper in $56^{\circ} \mathrm{C}$ incubator for at least one hour. 
1. Place volume of probe in a $1.5 \mathrm{ml}$ tube and bring volume up to $6 \mu l$ with TNE then add water to final volume of $30 \mu 1$. 2. Heat tube at $95-100{ }^{\circ} \mathrm{C}$ for 2 minutes then immediately place in cooler for 5 minutes.

3. After 5 minutes, spin for 2 seconds to retrieve condensation and add the following in order:

$10 \mu 15 x$ labeling Buffer

$2 \mu 1$ mixture of unlabeled dNTP's (ratio $1: 1: 1$ )

$2 \mu 1$ nuclease-free BSA

$5 \mu l\left\{C^{32}\right.$ P $\}$ dNTP (50uCi, 3000Ci/mmole)

5 units Klenow Enzyme

For a final volume of $50 \mu 1$

4. Spin tube for 2 seconds and incubate for 2 hours.

5. Remove caps from sephadex columns and decant liquid.

6. Fill columns with TE and decant.

7. Place column on Lucite rack and fill with TE. Remove bottom plugs and allow $\mathrm{TE}$ to flow through the column into waste container.

8. Add entire labeled probe volume to the Sephadex column and allow to completely enter filter. 
9. Add $400 \mu \mathrm{TE}$ to the Sephadex column and allow to run through into waste container.

10. Add $400 \mu \mathrm{TE}$ to column and collect the liquid as it is eluted. After probes are completed eluted dispose of columns.

11. Place $2 \mu \mathrm{l}$ of probe into the $1.5 \mathrm{ml}$ tube to determine total radioactivity.

12. Spin tube to be certain sample is located at bottom center where reading is taken with the Dupont Benchcount (model BC2000).

\section{HYDRIDIZATION}

1. Pre-hybridize the membrane with $20 \mathrm{ml}$ of the pre-warmed hybridization solution in a crew cap hybridization tube with $.5 \mathrm{ml}$ herring sperm for $20-30$ minutes in $65^{\circ} \mathrm{C}$ rotisserie oven.

2. Combine $0.5 \mathrm{ml}$ herring sperm DNA and the number of microliters calculated depending on the radioactivity reading from labeled probe.

3. Punch hole in cap to release pressure and place in $95^{\circ} \mathrm{C}$ heat block for 5 minutes. 
4. Immediately pipette the contents of the tube into $20 \mathrm{ml}$ of $56^{\circ} \mathrm{C}$ hybe solution, $\mathrm{mix}$ and add to the hybridization tube. Rotate overnight at $65^{\circ} \mathrm{C}$.

5. Pour off the hybridization solution and rinse membrane briefly in $2 \mathrm{X}$ SSC and discard solution.

6. Transfer membrane to a container and wash in $2 \mathrm{X}$ SSC:

$0.5 \% \operatorname{SDS}$ at $65^{\circ} \mathrm{C}$ for 10 minutes.

7. Pour off solution and rinse with $2 \mathrm{X}$ SSC.

8. Lightly blot the membrane and wrap in Saran wrap.

9. In darkroom place a piece of Kodak Biomax MS Scientific Imaging Film in a film cassette.

10. Tape the covered membrane on top of film so that the DNA side is in contact with the film. Close the film cassette.

11. Expose the film overnight at $-80^{\circ} \mathrm{C}$.

12. Process the film in the Konica Medical Film Processor $(Q X-70)$

CTT AMPLIFICATION USING PCR

1. Turn on Perkin Elmer Cetus Gene Amp 9600 PCR System approximately 30 minutes before use.

2. Determine volume of extracted sample needed from slot Blot so that approximately $3 \mathrm{ng}$ of DNA is added to reaction 
mix, bring up to final volume of $5 \mu 1$ with nuclease free water so that a total volume of $5 \mu \mathrm{l}$ is added to each reaction tube.

3. Add $1 \mu \mathrm{l}$ of $\mathrm{BSA}(8 \mathrm{mg} / \mathrm{ml})$ to DNA mixture.

4. To each microcentrifuge tube add $20 \mu l$ of master mix which contains the following:

$14.85 \mu l$ of nuclease free water

$2.5 \mu 1$ 10X STR Buffer

$2.5 \mu \mathrm{l}$ 10X CTT Primer

$0.15 \mu 1$ Taq Polymerase

5. Last add the $5 \mu 1$ of DNA mixture to the corresponding test tube.

6. Always include a positive and negative control. The positive control contains $20 \mu \mathrm{l}$ of master mix and $5 \mu \mathrm{l}$ of DNA mixture that is $2.5 \mu \mathrm{l}$ of $\mathrm{K} 562 \mathrm{DNA}$ and $2.5 \mu \mathrm{l}$ of nuclease free water. The negative control contains $20 \mu l$ of master $\operatorname{mix}$ and $5.0 \mu l$ of nuclease free water.

7. Mix each test tube using a vortex for approximately 2 seconds followed by centrifuging for approximately 2 seconds then place each test tube in the Perkin Elmer 9600 and amplify using the following protocol: 
Pre-denature $\quad 96{ }^{\circ} \mathrm{C} \quad 2$ minutes

Denature

$94{ }^{\circ} \mathrm{C} \quad 1$ minute

Anneal

$64{ }^{\circ} \mathrm{C}$

1 minute

for 10 cycles

Extend

$70{ }^{\circ} \mathrm{C}$

1.5 minutes

Denature

$90{ }^{\circ} \mathrm{C}$

1 minute

Anneal

$64{ }^{\circ} \mathrm{C}$

1 minute

for 20 cycles

Extend

$70{ }^{\circ} \mathrm{C} \quad 1.5$ minutes

PRODUCT GEL FOR VERIFICATION OF AMPLIFICATION

1. In an Erlenmeyer flask add 2 gm of ultra pure agarose and $100 \mathrm{ml}$ of $\mathrm{TBE}$ and microwave for approximately 3 minutes or until agar is dissolved completely.

2. Add $10 \mu l$ of ethidium bromide to flask and let cool to 56 ${ }^{\circ} \mathrm{C}$ and pour into $12 \times 15 \mathrm{~cm}$ gel tray, make sure well comb in place and let solidify (approximately 30 minutes).

3. Once solidified place in TBE electrophoresis tank and remove comb.

4. To the first well add $12 \mu 1$ of $\phi \chi 174$ as a marker to identify if triplex bands appear. 
5. To each consecutive well add the following mixture: $10 \mu l$ of amplified product for each sample and $2 \mu \mathrm{l}$ of loading solution without xylene cyanol.

6. Run gel at 100 volts for 60 minutes.

7. Once gel run is complete turn off power supply and view on Fotodyne UV light transilluminator.

8. Photograph the gel with Polaroid \#667 $8.5 \times 10.8 \mathrm{~cm}$ film with red filter in place.

9. Using $\varphi \chi 174$ as size standard, if three bands appear between base pair range of 118-310 then amplification was successful.

ANALYTICAL GEL

1. Prepare $4 \%$ or $6 \%$ (for the detection of the THO1 9.3

allele) denaturing polyacrylamide gel using the following:

Component

Urea

$\mathrm{DH}_{2} \mathrm{O}$

$10 \mathrm{X}$ TBE

$40 \%$ acrylamide: $\mathrm{bis}$
$4 \%$

$6 \%$

$31.50 \mathrm{~g}$

$40.00 \mathrm{ml}$

$3.75 \mathrm{ml}$

$7.50 \mathrm{ml}$

(19:1)
$31.50 \mathrm{~g}$

$36.25 \mathrm{ml}$

$3.75 \mathrm{ml}$

$11.25 \mathrm{ml}$ 
2. Filter gel solution through 0.2 micron filter (Nalgene tissue culture filter). Can be stored the light proof container at $4^{\circ}$ for up to three months.

3. Treat the shorter gel plate with fresh binding solution (prepare just before treating plate) made with $1.5 \mathrm{ml}$ of $0.5 \%$ acetic acid and $3 \mu l$ of bind silane.

4. Pour this mixture on cleaned shorter plate and spread with kim wipe in circular motion making sure to cover whole plate.

5. Let dry for 5 minutes and remove excess by wiping with 95\% ethanol on kim wipe four times, if not gel will stick to both short and long plate.

6. Treat longer plate with Gel Slick. Add $3 \mathrm{ml}$ of Gel Slick and spread with paper towel using circular motion.

7. Let dry for five minutes and remove excess with paper towel saturated with distilled water and let dry. 8. Assemble plates with treated sides facing each other separated by $0.4 \mathrm{~mm}$ side spacers and clamp with 4 clamps on each side leaving top and bottom unclamped.

9. Pour $32 \mathrm{ml}$ of gel solution in squirt bottle and add 250 $\mu l$ of ammonium persulfate and $25 \mu 1$ TEMED and swirl to mix. 10. Immediately pour gel from top of plate being careful not to let bubbles form till solution reaches bottom of 
plate and starts to drip out insert well comb at top on gel plates and clamp in place.

11. Let gel polymerize for at least one hour.

12. After gel has polymerized remove clamps and comb and shave away excess gel and clean plates with kim wipes saturated in deionized water.

13. Assemble plates in BRL model SA vertical

electrophoresis apparatus, make sure top drain closed and add $0.5 X$ TBE to top buffer chamber until well front is covered.

14. Make sure that buffer is not leaking between plates and apparatus and then add buffer to bottom chamber till it reach and slightly covers the bottom of the plates. 15. Using $100 \mathrm{CC}$ syringe filled with buffer and remove air bubbles and top of gel and any small pieces of polyacrylamide.

16. Pre-run gel at 40 watts for approximately 40 minutes or until reaches $50^{\circ} \mathrm{C}$.

17. While gel is pre running prepare PCR samples by taken $2.5 \mu \mathrm{l}$ of amplified product with $2.5 \mu \mathrm{l}$ of STR $2 \mathrm{X}$ loading solution and do the same for STR ladder. 
18. Denature sample and ladders for 2 minutes at $96{ }^{\circ} \mathrm{C}$ and immediately chill. Do this when gel pre- run is almost complete just before loading.

19. Once pre-run is complete at $3 \mu l$ of denatured sample mix in appropriate well, making sure that whole gel is loaded before it cools.

20. After gel is loaded with samples, ladders and positive and negative controls run at 40 watts for 55 minutes for $4 \%$ gel and 2 hours for 6\% gel.

21. Once gel run in complete turn off power supply, drain top chamber and then remove gel plates.

22. Using spatula separate plates, gel should stick to the short plate.

23. Now gel is ready for staining so that STR alleles can be assigned to each sample using the ladder as guide. 24. A 6\% Long Ranger Gel Solution was also used for the determination of the THO1 9.3 allele the following protocol was used.

25. The following mix was made prior to each gel run using Long Ranger Gel Solution:

$\begin{array}{ll}\text { 10X TBE } & 3.2 \mathrm{ml} \\ \text { Urea } & 13.44 \mathrm{gm} \\ \text { Ultrapure water } & \text { qs } 32 \mathrm{ml}\end{array}$


26. Follow plate treatment as stated above.

27. Prior to pouring gel add $160 \mu l$ 10\% ammonium persulfate and $16 \mu l$ Temed to gel mix.

28. Follow same directions as above to pour, pre-run and load gel.

29. Run at constant 40 watts for approximately 2 hours or till the second dye in the loading solution is about to run out of gel.

SILVER STAINING

1. Place gel in shallow plastic container in fix/stop solution for 20 minutes.

2. Pour fix/stop in another container for latter use.

3. Soak gel in deionized water for 2 minutes, repeat 2 more times discarding the water each time.

4. Soak gel in staining solution for 30 minutes then pour staining solution in silver precipitation container.

5. Rinse in deionized water again but only for 10 seconds.

6. Transfer gel to another shallow plastic container that is only used for developer solution and soak in developer for up to five minutes or until bands appear. 
7. Pour previously used fix/stop into container and soak for 5 minutes along with developer.

8. Pour out developer and fix/stop and soak gel in deionized water for 2 minutes.

9. All of the staining step are conducted while container is rocking slowly.

10. Once all step are completely the plate with gel affixed is let dry overnight in hood.

\section{EXPOSURE OF FILM}

1. Once gel is dry, place on counter in darkroom with gel side up.

2. Place a piece of Kodak 20.3 X 25.4 Duplicating Film with emulsion side facing the gel.

3. Make sure that film makes full contact with gel by running hand over the film.

4. Turn gel over so that film in now under plate and expose film by turning on overhead fluorescent light for 2 seconds.

5. Now take film off of gel and process in Konica Medical Film Processor QX-70. 
6. Once film is developed then the number of repeats for each sample for each loci can be determined by comparison with allelic ladder.

\section{III.RESULTS}

ALLELE ASSIGNMENT FOR BROWARD WHITES

\begin{tabular}{|l|l|l|l|}
\hline SAMPLE\# & CSF1PO & TPOX & THO1 \\
\hline BRW01 & 12,14 & 9,10 & 7,8 \\
\hline BRW02 & 12,15 & 8,11 & 9.3 \\
\hline BRW03 & 10,12 & 8,9 & $7,9.3$ \\
\hline BRW04 & 10,12 & 11 & $7,9.3$ \\
\hline BRW05 & 9,10 & 8,9 & 6 \\
\hline BRW06 & 11,12 & 8,10 & 7,8 \\
\hline BRW07 & 10,11 & 10,11 & $8,9.3$ \\
\hline BRW08 & 10,11 & 8,10 & $8,9.3$ \\
\hline BRW09 & 10 & 8,9 & $6,9.3$ \\
\hline BRW10 & 11 & 8 & 6,7 \\
\hline BRW11 & 10,12 & 8 & 7 \\
\hline BRW12 & 11 & 8,10 & $9,9.3$ \\
\hline BRW13 & 11,12 & 8,9 & 9.3 \\
\hline BRW14 & 10,12 & 8,11 & 7,10 \\
\hline BRW15 & 11,13 & 8 & 7,9 \\
\hline BRW16 & 11,12 & 8,10 & 7,8 \\
\hline BRW17 & 11,13 & 8,11 & 6,10 \\
\hline BRW18 & 11,12 & 11 & 7,9 \\
\hline BRW19 & 11,12 & 8,11 & 6,8 \\
\hline BRW20 & 11,12 & 8 & 7,8 \\
\hline BRW21 & 12,15 & 8 & 6,8 \\
\hline BRW22 & 11 & 8,9 & 6,7 \\
\hline BRW23 & 11,12 & 11,12 & 9.3 \\
\hline BRW24 & 10,12 & 11,12 & 7 \\
\hline BRW25 & 12 & 8 & 6,9 \\
\hline BRW26 & 9,10 & 8 & 8,9 \\
\hline BRW27 & 12,13 & 8,11 & $7,9.3$ \\
\hline BRW28 & 11,12 & 8,11 & 7,9 \\
\hline BRW29 & 10,11 & 8 & $9,9.3$ \\
\hline BRW30 & 11,12 & 8,9 & 7,9 \\
\hline BRW31 & 10,12 & 8,9 & $7,9.3$ \\
\hline & & & \\
\hline
\end{tabular}




\begin{tabular}{|l|l|l|l|}
\hline BRW32 & 11,12 & 8 & 6,9 \\
\hline BRW33 & 12 & 8,11 & 6,9 \\
\hline BRW34 & 11 & 8,11 & 9.3 \\
\hline BRW35 & 9,10 & 8,11 & 8,9 \\
\hline BRW36 & 11,12 & 8,11 & 6,9 \\
\hline BRW37 & 10,12 & 11 & 7,9 \\
\hline BRW38 & 11 & 8 & 6 \\
\hline BRW39 & 11,12 & 9,10 & $6,9.3$ \\
\hline BRW40 & 11,12 & 8,11 & 7,9 \\
\hline BRW41 & 12 & 8,11 & 6,7 \\
\hline BRW42 & 11,12 & 9,11 & $7,9.3$ \\
\hline BRW43 & 12,13 & 8,12 & $7,9.3$ \\
\hline BRW44 & 10,11 & 9 & 6 \\
\hline BRW45 & 11 & 8,11 & 7,8 \\
\hline BRW46 & 11,12 & 8,12 & $8,9.3$ \\
\hline BRW47 & 10,12 & 8,11 & 8,10 \\
\hline BRW48 & 11,12 & 9,11 & 6,9 \\
\hline BRW49 & 11,12 & 8,11 & 9 \\
\hline BRW50 & 9,11 & 8 & 6,8 \\
\hline BRW51 & 10,12 & 8,10 & 7,9 \\
\hline BRW52 & 12 & 8,9 & $6,9.3$ \\
\hline BRW53 & 11,12 & 9,11 & 9.3 \\
\hline BRW54 & 11,12 & 10,11 & $7,9.3$ \\
\hline BRW55 & 10 & 8,10 & 7,8 \\
\hline BRW56 & 9,11 & 8 & $6,9.3$ \\
\hline BRW57 & 12 & 8,9 & $7,9.3$ \\
\hline BRW58 & 11,12 & 8 & 7 \\
\hline BRW59 & 10 & 8,11 & $8,9.3$ \\
\hline BRW60 & 10 & 10,11 & 8,9 \\
\hline
\end{tabular}


ALLELE ASSIGNMENT FOR BROWARD BLACKS

\begin{tabular}{|l|l|l|l|}
\hline SAMPLE\# & CSF1PO & TPOX & THO1 \\
\hline BRB01 & 8,13 & 6,9 & 7 \\
\hline BRB02 & 10,11 & 11 & 6,7 \\
\hline BRB03 & 10,12 & 9,11 & 6,7 \\
\hline BRB04 & 10 & 8 & 7 \\
\hline BRB05 & 10 & 8,9 & 6,7 \\
\hline BRB06 & 8,14 & 7,8 & 6,7 \\
\hline BRB07 & 8,13 & 8,10 & 7,9 \\
\hline BRB08 & 10 & 8 & 6,7 \\
\hline BRB09 & 11 & 8,11 & $6,9.3$ \\
\hline BRB10 & 10,12 & 11 & 7 \\
\hline BRB11 & 12 & 9,10 & 7 \\
\hline BRB12 & 10,12 & 8 & 7,8 \\
\hline BRB13 & 7,11 & 8,9 & $8,9.3$ \\
\hline BRB14 & 10,12 & 8 & 7,8 \\
\hline BRB15 & 10,13 & 8 & 6,9 \\
\hline BRB16 & 10,11 & 6,11 & $8,9.3$ \\
\hline BRB17 & 9,10 & 9,10 & 7,8 \\
\hline BRB18 & 9,12 & 9 & 7,8 \\
\hline BRB19 & 10,12 & 6,8 & 7,9 \\
\hline BRB20 & 11,12 & 8,10 & 7 \\
\hline BRB21 & 10,11 & 11 & 7 \\
\hline BRB22 & 10 & 9 & 6,8 \\
\hline BRB23 & 10,12 & 7,10 & 7 \\
\hline BRB24 & 10,11 & 7,11 & 8,9 \\
\hline BRB25 & 10,11 & 8,12 & 8,9 \\
\hline BRB26 & 10,12 & 8,9 & 7,9 \\
\hline BRB27 & 8,12 & 8,11 & 8,9 \\
\hline BRB28 & 10,11 & 7 & 6,7 \\
\hline BRB29 & 12 & 9,12 & 8,9 \\
\hline BRB30 & 10,12 & 9,10 & 7,8 \\
\hline BRB31 & 11,12 & 8,11 & 8,9 \\
\hline BRB32 & 12,14 & 9,10 & 7,8 \\
\hline BRB33 & 8,12 & 8,11 & 6,9 \\
\hline BRB34 & 10,12 & 6,8 & 7 \\
\hline BRB35 & 10,12 & 8,9 & 7 \\
\hline BRB36 & 10 & 9,10 & 6,8 \\
\hline BRB37 & 11 & 8,11 & 8 \\
\hline BRB38 & 9,12 & 8,11 & 8,9 \\
\hline BRB39 & 10,12 & 6,9 & 7,9 \\
\hline BRB40 & 9,12 & 8 & 7,9 \\
\hline BRB41 & 7,12 & 8,11 & 7,9 \\
\hline & & & \\
\hline
\end{tabular}




\begin{tabular}{|l|l|l|l|}
\hline BRB42 & 9,10 & 6,10 & 7,8 \\
\hline BRB43 & 12,13 & 8,11 & 6,8 \\
\hline BRB44 & 12,13 & 11 & 7 \\
\hline BRB45 & 11,12 & 8,10 & 8,9 \\
\hline BRB46 & 9,11 & 10,11 & 7,8 \\
\hline BRB47 & 11,12 & 8 & 9 \\
\hline BRB48 & 10,11 & 8,9 & 6,7 \\
\hline BRB49 & 8,10 & 7,11 & 7,8 \\
\hline BRB50 & 10,12 & 8,11 & 6,8 \\
\hline BRB51 & 7,11 & 8 & 6,7 \\
\hline BRB52 & 10,11 & 11 & $6,9.3$ \\
\hline BRB53 & 11 & 8,9 & 9.3 \\
\hline BRB54 & 10,13 & 10,11 & $7,9.3$ \\
\hline BRB55 & 7,12 & 8,10 & 6 \\
\hline BRB56 & 11,12 & 12 & 7,9 \\
\hline BRB57 & 7,12 & 8 & 8 \\
\hline BRB58 & 10,13 & 7,9 & $8,9.3$ \\
\hline BRB59 & 9 & 8,12 & 6,7 \\
\hline BRB60 & 10,12 & 8 & $7,9.3$ \\
\hline
\end{tabular}


ALLELE ASSIGNMENTS FOR BAHAMIANS

\begin{tabular}{|l|l|l|l|}
\hline SAMPLE\# & CSF1PO & TPOX & THO1 \\
\hline BAH01 & 10 & 8,9 & $6,9.3$ \\
\hline BAH02 & 11,12 & 6,9 & 7,8 \\
\hline BAH03 & 10,12 & 9,11 & $8,9.3$ \\
\hline BAH04 & 11,12 & 9,10 & 6,9 \\
\hline BAH05 & 13 & 9 & $8,9.3$ \\
\hline BAH06 & 10,12 & 11 & 7 \\
\hline BAH07 & 8,12 & 10,11 & 7,8 \\
\hline BAH08 & 11,12 & 9 & $7,9.3$ \\
\hline BAH09 & 10,11 & 6,11 & 6,8 \\
\hline BAH10 & 10 & 11 & 7,8 \\
\hline BAH11 & 8,13 & 8,12 & 7,8 \\
\hline BAH12 & 11,13 & 8,10 & 6,7 \\
\hline BAH13 & 10,12 & 11 & 7,8 \\
\hline BAH14 & 10,12 & 8,9 & 7,9 \\
\hline BAH15 & 12 & 9,11 & 7 \\
\hline BAH16 & 11,12 & 8 & 8,9 \\
\hline BAH17 & 10,11 & 9 & 7 \\
\hline BAH18 & 9,13 & 6,11 & 7,8 \\
\hline BAH19 & 11,12 & 9 & 6 \\
\hline BAH20 & 11,12 & 8,9 & 8,9 \\
\hline BAH21 & 7,10 & 10 & 7,8 \\
\hline BAH22 & 11,13 & 8,11 & 6,7 \\
\hline BAH23 & 11,12 & 7,8 & 7,9 \\
\hline BAH24 & 7,10 & 8,9 & 7,8 \\
\hline BAH25 & 12 & 9,10 & 7,8 \\
\hline BAH26 & 11 & 9 & 7,8 \\
\hline BAH27 & 11,12 & 9,12 & $8,9.3$ \\
\hline BAH28 & 10 & 6,11 & 7 \\
\hline BAH29 & 7,15 & 6,9 & 8,9 \\
\hline BAH30 & 7,12 & 10,11 & 7 \\
\hline BAH31 & 10,12 & 8,9 & 7 \\
\hline BAH32 & 11,12 & 6,9 & 7,8 \\
\hline BAH33 & 8,10 & 9,11 & 7,9 \\
\hline BAH34 & 7,8 & 9,11 & 7,9 \\
\hline BAH35 & 11,12 & 8,9 & 8,10 \\
\hline BAH36 & 11 & 7,11 & 6,7 \\
\hline BAH37 & 10,11 & 8 & 8,9 \\
\hline BAH38 & 12 & 8,11 & 7 \\
\hline BAH39 & 11,12 & 10,11 & 9,10 \\
\hline BAH40 & 10,13 & 8,11 & 7,8 \\
\hline BAH41 & 7,12 & 8,11 & $7,9.3$ \\
\hline & & & \\
\hline
\end{tabular}




\begin{tabular}{|l|l|l|l|}
\hline BAH42 & 11 & 11 & 6,7 \\
\hline BAH43 & 11,12 & 6,11 & 6,8 \\
\hline BAH44 & 10,12 & 8,9 & 7,8 \\
\hline BAH45 & 11 & 6,11 & 9 \\
\hline BAH46 & 11,12 & 6,7 & 7,9 \\
\hline BAH47 & 7,10 & 6,8 & $7,9.3$ \\
\hline BAH48 & 11,12 & 10,12 & 7,8 \\
\hline BAH49 & 10,12 & 7,10 & 7,9 \\
\hline BAH50 & 12 & 9 & 8,9 \\
\hline BAH51 & 12,13 & 12,13 & 6,7 \\
\hline BAH52 & 10,11 & 8,10 & 7,9 \\
\hline BAH53 & 10,11 & 9 & $8,9.3$ \\
\hline BAH54 & 8,10 & 6,10 & 7,8 \\
\hline BAH55 & 12 & 8,11 & 7 \\
\hline BAH56 & 11 & 6,11 & 9.3 \\
\hline BAH57 & 9,11 & 8,11 & 6,7 \\
\hline BAH58 & 11,12 & 6,11 & 8,9 \\
\hline BAH59 & 11,12 & 6,11 & 6,7 \\
\hline BAH60 & 10,11 & 11 & 8 \\
\hline
\end{tabular}


ALLELE ASSIGNMENT FOR JAMAICANS

\begin{tabular}{|l|l|l|l|}
\hline SAMPLE\# & CSF1PO & TPOX & THO1 \\
\hline JAM01 & 10,11 & 9,11 & 7,8 \\
\hline JAM02 & 10,11 & 8,9 & 6,7 \\
\hline JAM03 & 11,13 & 6,8 & 7,8 \\
\hline JAM04 & 12,13 & 9,11 & $7,9.3$ \\
\hline JAM05 & 11 & 6 & 8 \\
\hline JAM06 & 12,13 & 9,10 & 7,9 \\
\hline JAM07 & 7,8 & 8,9 & 6,7 \\
\hline JAM08 & 10,12 & 8,9 & 6,9 \\
\hline JAM09 & 11,12 & 9 & 7,8 \\
\hline JAM10 & 10 & 9,11 & 7,8 \\
\hline JAM11 & 10 & 8 & 9,10 \\
\hline JAM12 & 12 & 8 & 7 \\
\hline JAM13 & 10 & 8,10 & 7 \\
\hline JAM14 & 10,12 & 8,11 & 6,8 \\
\hline JAM15 & 8,11 & 9,11 & 7 \\
\hline JAM16 & 11,13 & 8,12 & $7,9.3$ \\
\hline JAM17 & 12,14 & 8,9 & 7,8 \\
\hline JAM18 & 10,11 & 8 & 7,9 \\
\hline JAM19 & 9,10 & 10,11 & 6,9 \\
\hline JAM20 & 7,10 & 8,11 & 7 \\
\hline JAM21 & 8,9 & 9,10 & 7,8 \\
\hline JAM22 & 8,10 & 8,9 & 6,9 \\
\hline JAM23 & 7,11 & 6,9 & 6,9 \\
\hline JAM24 & 9,11 & 9 & 6,8 \\
\hline JAM25 & 11,12 & 8,11 & 7,8 \\
\hline JAM26 & 10,12 & 6,8 & 7,8 \\
\hline JAM27 & 11,12 & 8 & 8,10 \\
\hline JAM28 & 10,12 & 8,9 & 8,9 \\
\hline JAM29 & 12 & 9,10 & 7,8 \\
\hline JAM30 & 10,13 & 8,9 & 6,7 \\
\hline JAM31 & 10,11 & 8,11 & 6,7 \\
\hline JAM32 & 11,12 & 11 & 6,8 \\
\hline JAM33 & 9,10 & 8,11 & 8 \\
\hline JAM34 & 11,13 & 8 & $8,9.3$ \\
\hline JAM35 & 7,13 & 6,8 & 6,7 \\
\hline JAM36 & 8,12 & 11 & 6,7 \\
\hline JAM37 & 10 & 10,11 & 6,7 \\
\hline JAM38 & 9,10 & 8,10 & 6,9 \\
\hline JAM39 & 8,12 & 8 & 7,9 \\
\hline JAM40 & 10 & 10,11 & 7 \\
\hline JAM41 & 11,12 & 6,9 & 7 \\
\hline & & & \\
\hline
\end{tabular}




\begin{tabular}{|l|l|l|l|}
\hline JAM42 & 11,12 & 8,9 & 8 \\
\hline JAM43 & 11,12 & 9 & 6,7 \\
\hline JAM44 & 7,12 & 9 & $6,9.3$ \\
\hline JAM45 & 7,12 & 8 & 7,9 \\
\hline JAM46 & 7,10 & 11,12 & 7 \\
\hline JAM4 7 & 11,12 & 9,10 & 7,8 \\
\hline JAM48 & 9,10 & 9 & 7 \\
\hline JAM49 & 7,12 & 8,11 & 7 \\
\hline JAM50 & 11,12 & 9,11 & 7,8 \\
\hline JAM51 & 11,12 & 11,12 & 6,7 \\
\hline JAM52 & 7,8 & 6,9 & 7,9 \\
\hline JAM53 & 8 & 8,11 & 6,8 \\
\hline JAM54 & 10,13 & 9,11 & 6,7 \\
\hline JAM55 & 9,11 & 8,9 & 7 \\
\hline JAM56 & 10,11 & 6,11 & 6,8 \\
\hline JAM57 & 8,11 & 8,9 & 8 \\
\hline JAM58 & 7,11 & 9 & 7 \\
\hline JAM59 & 9,13 & 9,10 & 7,9 \\
\hline JAM60 & 7,10 & 7,12 & 7,9 \\
\hline
\end{tabular}


ALLELE ASSIGNMENTS FOR TRINIDADIANS

\begin{tabular}{|l|l|l|l|}
\hline SAMPLE\# & CSFIPO & TPOX & THO1 \\
\hline TRI01 & 12 & 9,12 & 7,8 \\
\hline TRI02 & 8,12 & 11,12 & 7,9 \\
\hline TRI03 & 11,14 & 9,12 & 7 \\
\hline TRI04 & 10,11 & 10,11 & 7,9 \\
\hline TRI05 & 11 & 6,8 & 7,8 \\
\hline TRI06 & 10,11 & 8,11 & 6,7 \\
\hline TRI07 & 10 & 8,11 & $6,9.3$ \\
\hline TRI08 & 12 & 10,11 & 7,9 \\
\hline TRI09 & 12 & 8,9 & 7 \\
\hline TRI10 & 8,12 & 11 & 6,9 \\
\hline TRI11 & 10,12 & 8,10 & 6,7 \\
\hline TRI12 & 10,11 & 8,9 & $9,9.3$ \\
\hline TRI13 & 8,13 & 7,8 & 6,9 \\
\hline TRI14 & 11,12 & 12,13 & 6,8 \\
\hline TRI15 & 8,11 & 8,11 & 6,8 \\
\hline TRI16 & 13 & 9 & 7,8 \\
\hline TRI17 & 13 & 8,10 & 8 \\
\hline TRI18 & 10 & 11 & 6,7 \\
\hline TRI19 & 7,10 & 6,8 & 9,10 \\
\hline TRI20 & 10,11 & 8,11 & 6,7 \\
\hline TRI21 & 8 & 8,10 & 6,7 \\
\hline TRI22 & 11 & 8,9 & 7,8 \\
\hline TRI23 & 10,11 & 8 & 7,8 \\
\hline TRI24 & 10,12 & 9,12 & 7,9 \\
\hline TRI25 & 7,12 & 8,11 & 7,9 \\
\hline TRI26 & 8,12 & 6,8 & 8,10 \\
\hline TRI27 & 8,9 & 7,10 & 7 \\
\hline TRI28 & 10,13 & 8 & 6,8 \\
\hline TRI29 & 10 & 6,11 & 7,8 \\
\hline TRI30 & 7,10 & 8 & 7 \\
\hline TRI31 & 7,10 & 6,11 & 7,9 \\
\hline TRI32 & 10,12 & 9,11 & $6,9.3$ \\
\hline TRI33 & 8,12 & 6,8 & 7 \\
\hline TRI34 & 12 & 8,11 & 9 \\
\hline TRI35 & 8,12 & 6,8 & 7,9 \\
\hline TRI36 & 10,12 & 10,11 & 6,8 \\
\hline TRI37 & 10,12 & 10,11 & 7,8 \\
\hline TRI38 & 7,11 & 8,11 & 7,8 \\
\hline TRI39 & 10 & 8,10 & 6,8 \\
\hline TRI40 & 10,11 & 9 & 7,8 \\
\hline TRI41 & 8,10 & 8 & 7,9 \\
\hline
\end{tabular}




\begin{tabular}{|l|l|l|l|}
\hline TRI42 & 9,12 & 9,11 & 6,8 \\
\hline TRI43 & 8,10 & 8,10 & 6,7 \\
\hline TRI44 & 8,12 & 8,9 & 7,9 \\
\hline TRI45 & 10,11 & 6,9 & 7 \\
\hline TRI46 & 7,12 & 11,12 & 8,9 \\
\hline TRI47 & 10,11 & 10,11 & 8,9 \\
\hline TRI48 & 11 & 9,11 & 7,8 \\
\hline TRI49 & 11,12 & 8,11 & 8,9 \\
\hline TRI50 & 10,12 & 11 & 7,8 \\
\hline TRI51 & 9,10 & 8,9 & 6 \\
\hline TRI52 & 10,12 & 8 & 7 \\
\hline TRI53 & 8,12 & 8 & 7,8 \\
\hline TRI54 & 11 & 9,10 & $8,9.3$ \\
\hline TRI55 & 12,13 & 8,11 & 6 \\
\hline TRI56 & 12 & 8,11 & 6 \\
\hline TRI57 & 10 & 8,11 & 8,9 \\
\hline TRI58 & 12 & 9,11 & 6,9 \\
\hline TRI59 & 11,12 & 8,11 & $6,9.3$ \\
\hline TRI60 & 11,12 & 8,11 & 8 \\
\hline
\end{tabular}


$\mathrm{F}_{S T}$ Values for $\mathrm{CSF}$

\begin{tabular}{|l|l|l|l|l|}
\hline & BB & BAH & JAM & TRI \\
\hline BW & 0.0154 & 0.0041 & 0.0179 & 0.0160 \\
\hline BB & & 0.0084 & 0.0040 & 0.0026 \\
\hline BAH & & & 0.0065 & 0.0064 \\
\hline JAM & & & & 0.0033 \\
\hline
\end{tabular}

$F_{S T}$ Values for TPOX

\begin{tabular}{|l|l|l|l|l|}
\hline & BB & BAH & JAM & TRI \\
\hline BW & 0.0085 & 0.0410 & 0.0240 & 0.0097 \\
\hline BB & & 0.0158 & 0.0081 & 0.0021 \\
\hline BAH & & & 0.0081 & 0.0125 \\
\hline JAM & & & & 0.0097 \\
\hline
\end{tabular}

$F_{S T}$ Values for THO1

\begin{tabular}{|l|l|l|l|l|}
\hline & BB & BAH & JAM & TRI \\
\hline BW & 0.0163 & 0.0203 & 0.0255 & 0.0166 \\
\hline BB & & 0.0017 & 0.0018 & 0.0198 \\
\hline BAH & & & 0.0038 & 0.0055 \\
\hline JAM & & & & 0.0039 \\
\hline
\end{tabular}

Average $F_{S T}$ Values for Loci

\begin{tabular}{|l|l|}
\hline CSF & .0085 \\
\hline TPOX & .0140 \\
\hline THO1 & .0115 \\
\hline
\end{tabular}

Average $F_{S T}$ Values by Population per Loci

\begin{tabular}{|c|c|c|c|}
\hline Population & CSF1PO & TPOX & THO1 \\
\hline BW & $.0134 \mathrm{sd} .0063$ & $.0208 \mathrm{sd} .0152$ & $.0197 \mathrm{sd} .0043$ \\
\hline$A D P *$ & $.0052 \mathrm{sd} .0022$ & $.0094 \mathrm{sd} .0046$ & $.0061 \mathrm{sd} .0069$ \\
\hline
\end{tabular}

$\star \mathrm{ADP}=$ African descent populations

sd.= standard deviation 


\section{IV.DISCUSSION}

This research was conducted to determine the $F_{S T}$ values for four populations of African descent in a PCR based system of indentification. These $\mathrm{F}_{\mathrm{ST}}$ estimates may be significant because forensic DNA match calculations of phenotypic frequency and likelihood ratios do not take into account population substructuring $(1-5)$. F ST $_{\text {values greatly affect }}$ probability calculations when alleles are rare, but alter estimates to a lesser extent when alleles are common. For example, when there are is an allele presnt with a frequency of 0.01 in a given population the probability ( $\left.\mathrm{p}^{\mathrm{a}}\right)$ of it occurring as a homozygote is 0.0001 or 1 out of 10,000. If an $F_{S T}$ value of .01 is used in the calculation

$\mathrm{p}^{2}+\mathrm{p}(1-\mathrm{p}) \mathrm{F}_{\mathrm{ST}}$ the match probability value changes to 0.0002 or 1 out of 5,000. Using an $F_{S T}$ value of .03, which is recommended by the National Research Council for a conservative estimate of $F_{S T}$ in a PCR based system, the match probability changes to 0.0004 or 1 out of $2,500(1)$. For a common allele with a frequency of 0.3 the probability $\left(\mathrm{p}^{2}\right)$ is .0 .09 or 1 out of 11.11 . Using $F_{S T}$ values of 0.01 and 
0.03 the probability changes to 0.0921 or 1 out of 10.86 and 0.0963 or 1 out of 10.38 , respectively. Average $F_{S T}$ estimates for all populations at STR locus CSF1PO equals 0.0085 , for TPOX it is 0.0140 and for THO1 it is 0.0115 . The average $F_{S T}$ value for Broward whites compared to African descent populations at CSF1PO equals .0134, at TPOX it equals 0.0208 and at THO1 it equals 0.0061 . This is in agreement with the general genetic observation that there is more substructuring between races than within races.

Since replicate allele frequencies effect $F_{S T}$ values the samples used were carefully chosen. They were selected from Broward Sheriff's office database of Broward whites, Broward blacks, Bahamians, Jamaicans, and Trinidadians. Sixty samples from each population were chosen based on the number of restriction fragment length polymorphisms (RFLP) sized in a previous study(12). All samples were sized at a minimum of four RFLP's. This ensured that no there were no samples repeated.

To test the significance of the $F_{S T}$ differences observed additional statistical tests were performed. The G -test results (Appendix XI) indicated that Broward whites and 
African descent populations are not homogeneous enough to be considered the same but all the African descent populations are homogeneous enough to be considered the same population(13) $\chi^{2}$ values (Appendix XII) suggest that genotype can be predicted from allele frequencies in Broward whites compared to African descent populations but not between African descent populations. A $\mathrm{T}$-test was conducted in order to determine whether the average $F_{S T}$ values were significant different between Broward whites and African descent populations. T values (Appendix XII \& XIV) suggest that the $F_{S T}$ average between Broward whites and African descent populations are significantly different and therefore the populations are significantly different yet the average for African descent populations are not significantly diferent and therefore the populations are not significantly different.

The National Research Council suggested that for PCR based systems a conservative $F_{S T}$ value of .03 may be used. For VNTR systems a value of .01 is a sufficient correction for subdivision. This is true for the populations used in this thesis $(12,15)$. This study determined that the use of $F_{S T}$ 
equal to 0.01 is sufficient for a PCR based system in the African descent populations used. 


\section{REFERENCES}

1.The Evaluation of Forensic DNA Evidence, National

Research Council, National Academy Press, Washington, D.C., 1996.

2.Budowle, B., "The Effects of Inbreeding on DNA Profile Frequency Estimates Using PCR Based Loci," Genetica, Vol. 96, 1995, pp.21-25.

3.Morton, N.E., "Genetic Structure of Forensic Populations," Proceeding of the National Academy of Science of the Unites States of America, Vol.89, 1992, pp.25562560.

4. Lewontin, R.C. and D. Hartl, "Population Genetics in Forensic DNA Typing," Science, Vol.254, 1991, pp.1745-1750. 5.Deka,R.,M.D.Shriver,L.M.Yu,R.E.Ferrell and R.Chakraborty, "Intra- and Inter- Population Diversity at Short Tandem Repeats in Diverse Populations of the World," Electrophoresis, Vol.16, 1995, pp.1659-1664. 6.Weir, B.and C.C.Cockerham, "Estimating F-Statistics for the Analysis of Population Structure," Evolution, Vol.38, 1994, pp. $1358-1370$.

7. Wright, S.,"The Interpretation of Population Structure by F-Statistics with Special Regard to Systems of Mating," Evolution, Vol.19, 1965, pp.395-420. 
8. Hartl, D.L. and A.G. Clark. "Principles of Population

Genetics, second edition," Sinauer Associates Inc., Sunderland, Massachusetts, 1989.

9. Sprecher, C.J.,C.Puers,A.M.Lins and J.W.Schumm, "General Approach to Analysis of Polymorphic Short Tandem Repeat Loci," Biotechniques, Vol.20, 1996, pp.266-276. 10.Crouse, C. and J.Schumm,"Investigation of Species Specificity Using a PCR-based Human STR System," Journal of Forensic Science, Vol.40, 1995, pp.952-956.

11.Micka, K., C.J.Sprecher, A.M.Lins, C.T.Comey, B.W. Koons, C.Crouse, D.Endean, K.Zold, S.Lee, N.Duda, M.Ma, and J.Schumm, "Validation of Multiplex Polymorphic STR Amplification Sets Developed for Personal Identification," Fifth International Symposium on Human Identification, 1994.

12. Noppinger,K., "VNTR Heterogeneity Among Caribbean Populations," Masters' thesis, Florida International University, Miami, 1996.

13. Sokal, R. and F.J. Rohlf, Biometry, second edition, WH Freeman and Company, San Francisco, 1986. 14.McClave, J.T. and F.H. Dietrich II, Statistics, fifth edition, Dellen Publishing, San Francisco,1991. 
15.Duncan, G.T.,K. Noppinger, J.Carey, and M.Tracey,

"Comparison of VNTR Allele Frequencies and Inclusion

Probabilities Over Six Populations" Genetica, Vol.88, 1993, pp. 51-57. 


\section{APPENDIX I}

REAGENTS USED

\section{$0.5 \%$ Acetic Acid}

Glacial acetic acid $50 \mathrm{ml}$

$\mathrm{dH}_{2} \mathrm{O} \quad 950 \mathrm{ml}$

0.58 Acetic Acid in 958 Ethanol

Glacial acetic acid $1 \mathrm{ml}$

95\% Ethanol $199 \mathrm{ml}$

408 Acrylamide:bis

Acrylamide $\quad 380 \mathrm{~g}$

Bisacrlamide $\quad 20 \mathrm{~g}$

Dissolve above in $500 \mathrm{ml} \mathrm{d} \mathrm{H}_{2} \mathrm{O}$

then bring up to volume of $1 \mathrm{~L}$

\section{Ammonium Persulfate}

ammonium persulfate $0.5 \mathrm{~g}$

$\mathrm{dH}_{2} \mathrm{O} \quad 5 \mathrm{ml}$

Store in freezer in $250 \mu \mathrm{l}$

aliquots 
BSA

Bovine serum albumin $8 \mathrm{mg}$ Nuclease free water $1 \mathrm{ml}$

CTT Primer

Obtained from Promega in the

Geneprint STR Triplex CTT kit

Developing Solution

37\% Formaldehyde $\quad 1.5 \mathrm{ml}$

Sodium Thiosulfate $200 \mu l$

$\mathrm{dH}_{2} \mathrm{O}$

$1000 \mathrm{ml}$

Sodium Carbonate $\quad 30 \mathrm{~g}$

708 Ethanol

Reagent alcohol $700 \mathrm{ml}$

$\mathrm{dH}_{2} \mathrm{O} \quad 300 \mathrm{ml}$

Ethidium Bromide

${\mathrm{dH_{2 }}} \mathrm{O} \quad 40 \mathrm{ml}$

Ethidium Bromide $0.2 \mathrm{~g}$

Fix/Stop

Glacial acetic acid $100 \mathrm{ml}$

$\mathrm{DH}_{2} \mathrm{O} \quad 900 \mathrm{ml}$

Herring Sperm DNA

Herring Sperm DNA 500mg

q.s. to $50 \mathrm{ml}$ of $\mathrm{dH}_{2} \mathrm{O}$

Denature in boiling water

for 5 minutes, aliqout $500 \mu l$

in screw cap tubes 


\section{Hybridization Solution}

\begin{tabular}{lc}
\hline $20 X$ SSPE & $250 \mathrm{ml}$ \\
$20 \% \mathrm{SDS}$ & $25 \mathrm{ml}$ \\
$\mathrm{dH}_{2} \mathrm{O}$ & $725 \mathrm{ml}$
\end{tabular}

Warm solution before use to ensure solids dissolved

Loading Buffer (Yield Gel)

\begin{tabular}{ll}
\hline Tris $0.5 \mathrm{M}$ & $1.0 \mathrm{ml}$ \\
$\mathrm{TE}$ & $5.0 \mathrm{ml}$ \\
Ficoll & $1.0 \mathrm{~g}$ \\
$\mathrm{dH}_{2} \mathrm{O}$ & $4.0 \mathrm{ml}$ \\
Bromophenol Blue & $0.025 \mathrm{~g}$
\end{tabular}

Phenol/Chloroform/Isoamyl Alcohol

Phenol $340 \mathrm{ml}$

Chloroform $\quad 340 \mathrm{ml}$

Isoamyl alcohol $\quad 13.6 \mathrm{ml}$

8-Hydroxyquinoline $\quad 0.68 \mathrm{~g}$

Store in brown bottles

Prewetting solution

Sodium Hydroxide $16 \mathrm{~g}$

EDTA $9.3 \mathrm{~g}$

Dissolve sodium hydroxide in $1 \mathrm{~L}$

Of water to yield $0.4 \mathrm{~N}$ Sodium Hydroxide

Dissolve EDTA in $1 \mathrm{~L}$ of $0.4 \mathrm{~N}$ Sodium Hydroxide

\section{Proteinase $\mathrm{K}$}

$\overline{\text { Proteinase } \mathrm{K}} \quad 500 \mathrm{mg}$

$\mathrm{dH}_{2} \mathrm{O} \quad 25 \mathrm{ml}$

Aliqout in $250 \mu l$ and freeze 
SDS

$\overline{\mathrm{SDS}}$ $200 \mathrm{~g}$

$\mathrm{dH}_{2} \mathrm{O}$ $700 \mathrm{ml}$

Heat to $65{ }^{\circ} \mathrm{C}$ to dissolve, adjust volume to $1 \mathrm{~L}$

Sodium Thiosulfate

Sodium Thiosulfate $5 \mathrm{~g}$

$\mathrm{dH}_{2} \mathrm{O}$

$500 \mathrm{ml}$

Spotting solution

$0.4 \mathrm{~N}$ Sodium Hydroxide/

25mM EDTA

$100 \mathrm{ml}$

Sprinkle with bromophenol blue

SSC

Sodium Chloride $\quad 526 \mathrm{~g}$

$\mathrm{Na}_{3}$ Citrate: $2 \mathrm{H}_{2} \mathrm{O} \quad 265 \mathrm{~g}$

$\mathrm{dH}_{2} \mathrm{O} \quad 2400 \mathrm{ml}$

$\mathrm{pH}$ to 7.0 with $\mathrm{HCl}, \mathrm{q} . \mathrm{s}$ to $3 \mathrm{~L}$

\section{SSPE}

Sodium Chloride $\quad 841.6 \mathrm{~g}$

Sodium Phoshate $\quad 96 \mathrm{~g}$

$\mathrm{pH}$ to 7.0 with $10 \mathrm{M}$ Sodium Hydroxide

$0.5 \mathrm{M}$ EDTA

$\mathrm{dH}_{2} \mathrm{O}$

$160 \mathrm{ml}$

$4 \mathrm{~L}$

Stain Extraction Buffer
$10 \mathrm{mM}$ Tris
$1.21 \mathrm{~g}$
$0.1 \mathrm{M} \mathrm{NaCl}$
$5.84 \mathrm{~g}$
$0.01 \mathrm{M} \mathrm{Na} 2 \mathrm{EDTA}-2 \mathrm{H}_{2} \mathrm{O}$
$3.72 \mathrm{~g}$
Dissolve Tris and $\mathrm{NaCl}$ in $500 \mathrm{ml}$ $\mathrm{dH}_{2} \mathrm{O}$, adjust $\mathrm{pH}$ to 8.0 with $\mathrm{NaOH}$. Add $\mathrm{Na}_{2} \mathrm{EDTA}-2 \mathrm{H}_{2} \mathrm{O}$, add $100 \mathrm{ml} 20 \%$
SDS. Adjust volume to $1 \mathrm{~L}$ with $\mathrm{dH}_{2} \mathrm{O}$. 
Staining Solution

\begin{tabular}{lc}
\hline Silver Nitrate & $1 \mathrm{~g}$ \\
$\mathrm{dH}_{2} \mathrm{O}$ & $100 \mathrm{ml}$ \\
$37 \%$ Formaldehyde & $1.5 \mathrm{ml}$
\end{tabular}

STR Buffer

Obtained from Promega in

Geneprint STR Triplex CTT kit

STR Loading Solution

obtained from Promega in

Geneprint STR Triplex CTT kit

\section{$50 \%$ TAE}

Tris base $242 \mathrm{~g}$

Glacial acetic acid $57.1 \mathrm{ml}$

$0.5 \mathrm{M}$ EDTA

$100 \mathrm{ml}$

Add Tris base and EDTA to $500 \mathrm{ml}$

of $\mathrm{dH}_{2} \mathrm{O}$. Add glacial acetic acid, q.s to $1000 \mathrm{ml}$ with $\mathrm{dH}_{2} \mathrm{O}$.

10X TBE

Tris base

EDTA

$107.8 \mathrm{~g}$

$7.44 \mathrm{~g}$

Boric acid (approx.)55.0 g

Dissolve Tris base and EDTA in $800 \mathrm{ml}$

$\mathrm{dH}_{2} \mathrm{O}$. Slowly add boric acid and monitor $\mathrm{pH}$

until obtain $\mathrm{pH}$ of $8.3, \mathrm{q} . \mathrm{s}$ to $1 \mathrm{~L}$ with

$\mathrm{H}_{2} \mathrm{O}$. 
TE

Tris base

$1.21 \mathrm{~g}$

EDTA

$0.037 \mathrm{~g}$

Dissolve Tris base and EDTA in $900 \mathrm{ml}$

$\mathrm{dH}_{2} \mathrm{O}$. Adjust to $\mathrm{pH} 7.5$ with $\mathrm{HCl}$, q.s to

1 L with $\mathrm{dH}_{2} \mathrm{O}$.

\section{TNE}

Tris base

$0.121 \mathrm{~g}$

$\mathrm{NaCl}$

$0.584 \mathrm{~g}$

$\mathrm{Na}_{2} \mathrm{EDTA}-2 \mathrm{H}_{2} \mathrm{O}$

$0.037 \mathrm{~g}$

Dissolve in $80 \mathrm{ml} \mathrm{dH}_{2} \mathrm{O}$, adjust to $\mathrm{pH} 8.0$

With $\mathrm{NaOH}, q . \mathrm{s}$ to $1 \mathrm{~L}$ with $\mathrm{dH}_{2} \mathrm{O}$.

\section{$\varphi \times 174$}

$\phi \chi 174 \mathrm{RF}$ (HAE Fragment) to a concentration of $100 \mathrm{ng} / 6 \mu \mathrm{l}$. 
YIELD GEL RESULTS FOR BROWARD WHITES

\begin{tabular}{|l|l|l|l|}
\hline SAMPLE \# & DNA (ng) & SAMPLE \# & DNA (ng) \\
\hline BRW01 & $15<$ & BRW31 & $15<$ \\
\hline BRW02 & 0 & BRW32 & 15 \\
\hline BRW03 & 250 & BRW33 & 15 \\
\hline BRW04 & 15 & BRW34 & 15 \\
\hline BRW05 & 0 & BRW35 & 31 \\
\hline BRW06 & 0 & BRW36 & 63 \\
\hline BRW07 & 15 & BRW37 & 0 \\
\hline BRW08 & $15<$ & BRW38 & 15 \\
\hline BRW09 & 63 & BRW39 & 0 \\
\hline BRW10 & 31 & BRW40 & 15 \\
\hline BRW11 & 0 & BRW41 & $15<$ \\
\hline BRW12 & $15<$ & BRW42 & 15 \\
\hline BRW13 & 250 & BRW43 & 15 \\
\hline BRW14 & 15 & BRW44 & 15 \\
\hline BRW15 & 0 & BRW45 & 31 \\
\hline BRW16 & 31 & BRW46 & 15 \\
\hline BRW17 & 31 & BRW47 & 15 \\
\hline BRW18 & 15 & BRW48 & $15<$ \\
\hline BRW19 & 15 & BRW49 & $15<$ \\
\hline BRW20 & 63 & BRW50 & 0 \\
\hline BRW21 & 30 & BRW51 & 15 \\
\hline BRW22 & $15<$ & BRW52 & 31 \\
\hline BRW23 & $15<$ & BRW53 & 15 \\
\hline BRW24 & 15 & BRW54 & 250 \\
\hline BRW25 & 15 & BRW55 & 31 \\
\hline BRW26 & $15<$ & BRW56 & 0 \\
\hline BRW27 & $15<$ & BRW57 & 0 \\
\hline BRW28 & $15<$ & BRW58 & 15 \\
\hline BRW29 & $15<$ & BRW59 & 31 \\
\hline BRW30 & 0 & BRW60 & 15 \\
\hline & & & \\
\hline
\end{tabular}


YIELD GEL RESULTS FOR BROWARD BLACKS

\begin{tabular}{|l|l|l|l|}
\hline SAMPLE \# & DNA (ng) & SAMPLE \# & DNA (ng) \\
\hline BRB01 & 500 & BRB31 & 125 \\
\hline BRB01 & $15<$ & BRB32 & 250 \\
\hline BRB03 & 0 & BRB33 & 125 \\
\hline BRB04 & 0 & BRB34 & 63 \\
\hline BRB05 & 500 & BRB35 & 125 \\
\hline BRB06 & 125 & BRB36 & 0 \\
\hline BRB07 & 63 & BRB37 & 250 \\
\hline BRB08 & 15 & BRB38 & 15 \\
\hline BRB09 & 15 & BRB39 & 125 \\
\hline BRB10 & $15<$ & BRB40 & 250 \\
\hline BRB11 & $15<$ & BRB41 & 125 \\
\hline BRB12 & 15 & BRB42 & 250 \\
\hline BRB13 & 15 & BRB43 & 15 \\
\hline BRB14 & 63 & BRB44 & 31 \\
\hline BRB15 & 15 & BRB45 & 125 \\
\hline BRB16 & 0 & BRB46 & 7.5 \\
\hline BRB17 & 0 & BRB47 & 63 \\
\hline BRB18 & 15 & BRB48 & 15 \\
\hline BRB19 & 125 & BRB49 & 15 \\
\hline BRB20 & 15 & BRB50 & 63 \\
\hline BRB21 & $15<$ & BRB51 & 125 \\
\hline BRB22 & 0 & BRB52 & 0 \\
\hline BRB23 & 31 & BRB53 & 63 \\
\hline BRB24 & 15 & BRB54 & 31 \\
\hline BRB25 & 0 & BRB55 & $500>$ \\
\hline BRB26 & 125 & BRB56 & 15 \\
\hline BRB27 & 31 & BRB57 & 500 \\
\hline BRB28 & 63 & BRB58 & $15<$ \\
\hline BRB29 & $15<$ & BRB59 & 31 \\
\hline BRB30 & 125 & BRB60 & $15<$ \\
\hline
\end{tabular}


YIELD GEL RESULTS FOR BAHAMIANS

\begin{tabular}{|l|l|l|l|}
\hline SAMPLE \# & DNA $(\mathrm{ng})$ & SAMPLE\# & DNA (ng) \\
\hline BAH01 & 7.5 & BAH31 & 63 \\
\hline BAH02 & 31 & BAH32 & 15 \\
\hline BAH03 & $15<$ & BAH33 & 63 \\
\hline BAH04 & 7.5 & BAH34 & 15 \\
\hline BAH05 & 0 & BAH35 & $15<$ \\
\hline BAH06 & $15<$ & BAH36 & 15 \\
\hline BAH07 & $15<$ & BAH37 & $15<$ \\
\hline BAH08 & $15<$ & BAH38 & 7.5 \\
\hline BAH09 & 0 & BAH39 & $15<$ \\
\hline BAH10 & 15 & BAH40 & 0 \\
\hline BAH11 & 31 & BAH41 & 15 \\
\hline BAH12 & 31 & BAH42 & 15 \\
\hline BAH13 & 31 & BAH43 & 15 \\
\hline BAH14 & $15<$ & BAH44 & 15 \\
\hline BAH15 & 31 & BAH45 & $15<$ \\
\hline BAH16 & 31 & BAH46 & 15 \\
\hline BAH17 & 31 & BAH47 & 15 \\
\hline BAH18 & 15 & BAH48 & 15 \\
\hline BAH19 & 15 & BAH49 & 31 \\
\hline BAH20 & 15 & BAH50 & 15 \\
\hline BAH21 & $15<$ & BAH51 & $15<$ \\
\hline BAH22 & 0 & BAH52 & $15<$ \\
\hline BAH23 & 0 & BAH53 & 15 \\
\hline BAH24 & 0 & BAH54 & 15 \\
\hline BAH25 & $15<$ & BAH55 & $15<$ \\
\hline BAH26 & $15<$ & BAH56 & 0 \\
\hline BAH27 & $15<$ & BAH57 & $15<$ \\
\hline BAH28 & 15 & BAH58 & 15 \\
\hline BAH29 & 0 & BAH59 & 15 \\
\hline BAH30 & 0 & BAH60 & 22.5 \\
\hline
\end{tabular}


YIELD GEL RESULTS FOR JAMAICANS

\begin{tabular}{|l|l|l|l|}
\hline SAMPLE \# & DNA $(\mathrm{ng})$ & SAMPLE \# & DNA $(\mathrm{ng})$ \\
\hline JAM01 & 31 & JAM31 & 63 \\
\hline JAM02 & 31 & JAM32 & 15 \\
\hline JAM03 & 31 & JAM33 & 0 \\
\hline JAM04 & 63 & JAM34 & $15<$ \\
\hline JAM05 & 15 & JAM35 & 15 \\
\hline JAM06 & $15<$ & JAM36 & $15<$ \\
\hline JAM07 & 7.5 & JAM37 & 15 \\
\hline JAM08 & 15 & JAM38 & 15 \\
\hline JAM09 & 15 & JAM39 & 31 \\
\hline JAM10 & 15 & JAM40 & 250 \\
\hline JAM11 & $15<$ & JAM41 & 15 \\
\hline JAM12 & 15 & JAM42 & 31 \\
\hline JAM13 & 15 & JAM43 & 125 \\
\hline JAM14 & $15<$ & JAM44 & 125 \\
\hline JAM15 & 31 & JAM45 & 31 \\
\hline JAM16 & 0 & JAM46 & 63 \\
\hline JAM17 & 7.5 & JAM47 & 63 \\
\hline JAM18 & 15 & JAM48 & 125 \\
\hline JAM19 & 15 & JAM49 & 125 \\
\hline JAM20 & 31 & JAM50 & 125 \\
\hline JAM21 & 63 & JAM51 & 250 \\
\hline JAM22 & 125 & JAM52 & 125 \\
\hline JAM23 & 15 & JAM53 & 125 \\
\hline JAM24 & 15 & JAM54 & 31 \\
\hline JAM25 & 15 & JAM55 & 31 \\
\hline JAM26 & 15 & JAM56 & $15<$ \\
\hline JAM27 & $15<$ & JAM57 & 15 \\
\hline JAM28 & 63 & JAM58 & 63 \\
\hline JAM29 & 125 & JAM59 & 15 \\
\hline JAM30 & 31 & JAM60 & 63 \\
\hline & & & \\
\hline
\end{tabular}


YIELD GEL RESULTS FOR TRINIDADIANS

\begin{tabular}{|l|l|l|l|}
\hline SAMPLE \# & DNA $(\mathrm{ng})$ & SAMPLE \# & DNA (ng) \\
\hline TRI01 & 15 & TRI31 & 0 \\
\hline TRI02 & 0 & TRI32 & 63 \\
\hline TRI03 & 31 & TRI33 & 125 \\
\hline TRI04 & 15 & TRI34 & 31 \\
\hline TRI05 & 15 & TRI35 & $15<$ \\
\hline TRI06 & 0 & TRI36 & 15 \\
\hline TRI07 & 31 & TRI37 & 31 \\
\hline TRI08 & 0 & TRI38 & 0 \\
\hline TRI09 & 7.5 & TRI39 & 0 \\
\hline TRI10 & 0 & TRI40 & $15<$ \\
\hline TRI11 & $15<$ & TRI41 & 63 \\
\hline TRI12 & $15<$ & TRI42 & 31 \\
\hline TRI13 & 31 & TRI43 & 63 \\
\hline TRI14 & 7.5 & TRI44 & 63 \\
\hline TRI15 & $15<$ & TRI45 & $15<$ \\
\hline TRI16 & 15 & TRI46 & 7.5 \\
\hline TRI17 & 0 & TRI47 & 15 \\
\hline TRI18 & 0 & TRI48 & $15<$ \\
\hline TRI19 & 7.5 & TRI49 & $15<$ \\
\hline TRI20 & $15<$ & TRI50 & 15 \\
\hline TRI21 & 0 & TRI51 & 15 \\
\hline TRI22 & 0 & TRI52 & 125 \\
\hline TRI23 & 0 & TRI53 & $15<$ \\
\hline TRI24 & $15<$ & TRI54 & $15<$ \\
\hline TRI25 & 0 & TRI55 & 31 \\
\hline TRI26 & 0 & TRI56 & $15<$ \\
\hline TRI27 & 15 & TRI57 & $15<$ \\
\hline TRI28 & 15 & TRI58 & 250 \\
\hline TRI29 & 15 & TRI59 & 15 \\
\hline TRI30 & 0 & TRI60 & 63 \\
\hline & & & \\
\hline
\end{tabular}




\section{APPENDIX III}

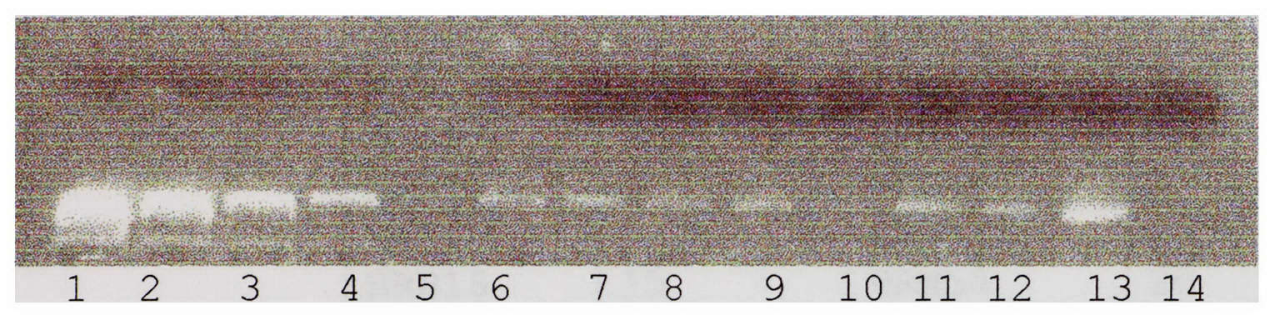

FIGURE 1: Scan of polaroid of yield gel. Lanes 1- 6 contain the following standards in ng of DNA: 500, $250,125,63,15,30$. Lanes $8-13$ contain samples 
SLOT BLOT RESULTS FOR BROWARD WHITE

\begin{tabular}{|l|l|l|l|}
\hline SAMPLE \# & DNA (ng) & SAMPLE \# & DNA (ng) \\
\hline BRW02 & 10 & BRW25 & 10 \\
\hline BRW03 & 30 & BRW26 & 15 \\
\hline BRW04 & 30 & BRW30 & 10 \\
\hline BRW05 & 10 & BRW32 & 20 \\
\hline BRW06 & 30 & BRW35 & 2.5 \\
\hline BRW09 & 30 & BRW40 & 15 \\
\hline BRW11 & 5 & BRW41 & 5 \\
\hline BRW15 & 1.25 & BRW51 & 25 \\
\hline BRW16 & 15 & BRW58 & 20 \\
\hline BRW18 & 10 & BRW59 & 30 \\
\hline BRW19 & 10 & BRW60 & 25 \\
\hline
\end{tabular}

SLOT BLOT RESULTS FOR BROWARD BLACKS

\begin{tabular}{|l|l|l|l|}
\hline SAMPLE \# & DNA (ng) & SAMPLE \# & DNA (ng) \\
\hline BRB02 & 10 & BRB27 & 20 \\
\hline BRB03 & 7.5 & BRB28 & 30 \\
\hline BRB04 & 5 & BRB34 & 10 \\
\hline BRB06 & 10 & BRB35 & 40 \\
\hline BRB08 & 10 & BRB36 & 5 \\
\hline BRB10 & 10 & BRB37 & 60 \\
\hline BRB11 & 15 & BRB38 & 10 \\
\hline BRB12 & 10 & BRB39 & 10 \\
\hline BRB14 & 30 & BRB40 & 30 \\
\hline BRB15 & 10 & BRB41 & 30 \\
\hline BRB16 & 30 & BRB43 & 10 \\
\hline BRB17 & 30 & BRB45 & 30 \\
\hline BRB18 & 20 & BRB47 & 20 \\
\hline BRB20 & 10 & BRB50 & 20 \\
\hline BRB22 & 15 & BRB51 & 30 \\
\hline BRB23 & 15 & BRB55 & 20 \\
\hline BRB24 & 5 & BRB58 & 15 \\
\hline BRB25 & 20 & BRB60 & 10 \\
\hline
\end{tabular}


SLOT BLOT RESULTS FOR BAHAMIANS

\begin{tabular}{|l|l|l|l|}
\hline SAMPLE \# & DNA (ng) & SAMPLE \# & DNA (ng) \\
\hline BAH02 & 5 & BAH28 & 10 \\
\hline BAH06 & .625 & BAH29 & 30 \\
\hline BAH08 & 2.5 & BAH30 & 30 \\
\hline BAH09 & 2.5 & BAH31 & 10 \\
\hline BAH10 & 2.5 & BAH32 & 5 \\
\hline BAH11 & 5 & BAH33 & 2.5 \\
\hline BAH12 & 10 & BAH34 & 10 \\
\hline BAH13 & 5 & BAH36 & 10 \\
\hline BAH15 & 5 & BAH41 & 20 \\
\hline BAH16 & 5 & BAH42 & 20 \\
\hline BAH17 & 5 & BAH43 & 20 \\
\hline BAH18 & 10 & BAH44 & 20 \\
\hline BAH19 & 5 & BAH46 & 20 \\
\hline BAH20 & 5 & BAH47 & 20 \\
\hline BAH22 & 10 & BAH48 & 20 \\
\hline BAH23 & 5 & BAH49 & 20 \\
\hline BAH24 & 2.5 & BAH50 & 20 \\
\hline BAH25 & 15 & BAH53 & 10 \\
\hline BAH27 & 15 & BAH54 & 5 \\
\hline
\end{tabular}

\section{SLOT BLOT RESULTS FOR JAMAICANS}

\begin{tabular}{|l|l|l|l|}
\hline SAMPLE \# & DNA (ng) & SAMPLE\# & DNA (ng) \\
\hline JAM01 & 10 & JAM35 & 30 \\
\hline JAM02 & 10 & JAM37 & 30 \\
\hline JAM04 & 10 & JAM38 & 5 \\
\hline JAM05 & 10 & JAM39 & 30 \\
\hline JAM08 & 15 & JAM40 & 20 \\
\hline JAM09 & 5 & JAM43 & 20 \\
\hline JAM11 & 5 & JAM44 & 20 \\
\hline JAM13 & 5 & JAM45 & 63 \\
\hline JAM14 & 5 & JAM46 & 20 \\
\hline JAM15 & 10 & JAM47 & 20 \\
\hline JAM18 & 15 & JAM48 & 20 \\
\hline JAM19 & 5 & JAM49 & 20 \\
\hline JAM27 & 15 & JAM50 & 20 \\
\hline
\end{tabular}




\begin{tabular}{|l|l|l|l|}
\hline JAM28 & 20 & JAM51 & 20 \\
\hline JAM30 & 15 & JAM52 & 20 \\
\hline JAM32 & 20 & JAM53 & 20 \\
\hline JAM34 & 30 & & \\
\hline
\end{tabular}

SLOT BLOT RESULTS FOR TRINIDADIANS

\begin{tabular}{|l|l|l|l|}
\hline SAMPLE \# & DNA (ng) & SAMPLE \# & DNA (ng) \\
\hline TRI01 & 10 & TRI21 & 15 \\
\hline TRI03 & 10 & TRI25 & 15 \\
\hline TRI04 & 10 & TRI26 & 2.5 \\
\hline TRI07 & 10 & TRI27 & 10 \\
\hline TRI10 & 5 & TRI28 & 5 \\
\hline TRI12 & 10 & TRI29 & 10 \\
\hline TRI13 & 10 & TRI43 & 20 \\
\hline TRI17 & 10 & TRI44 & 30 \\
\hline
\end{tabular}




\section{APPENDIX V}

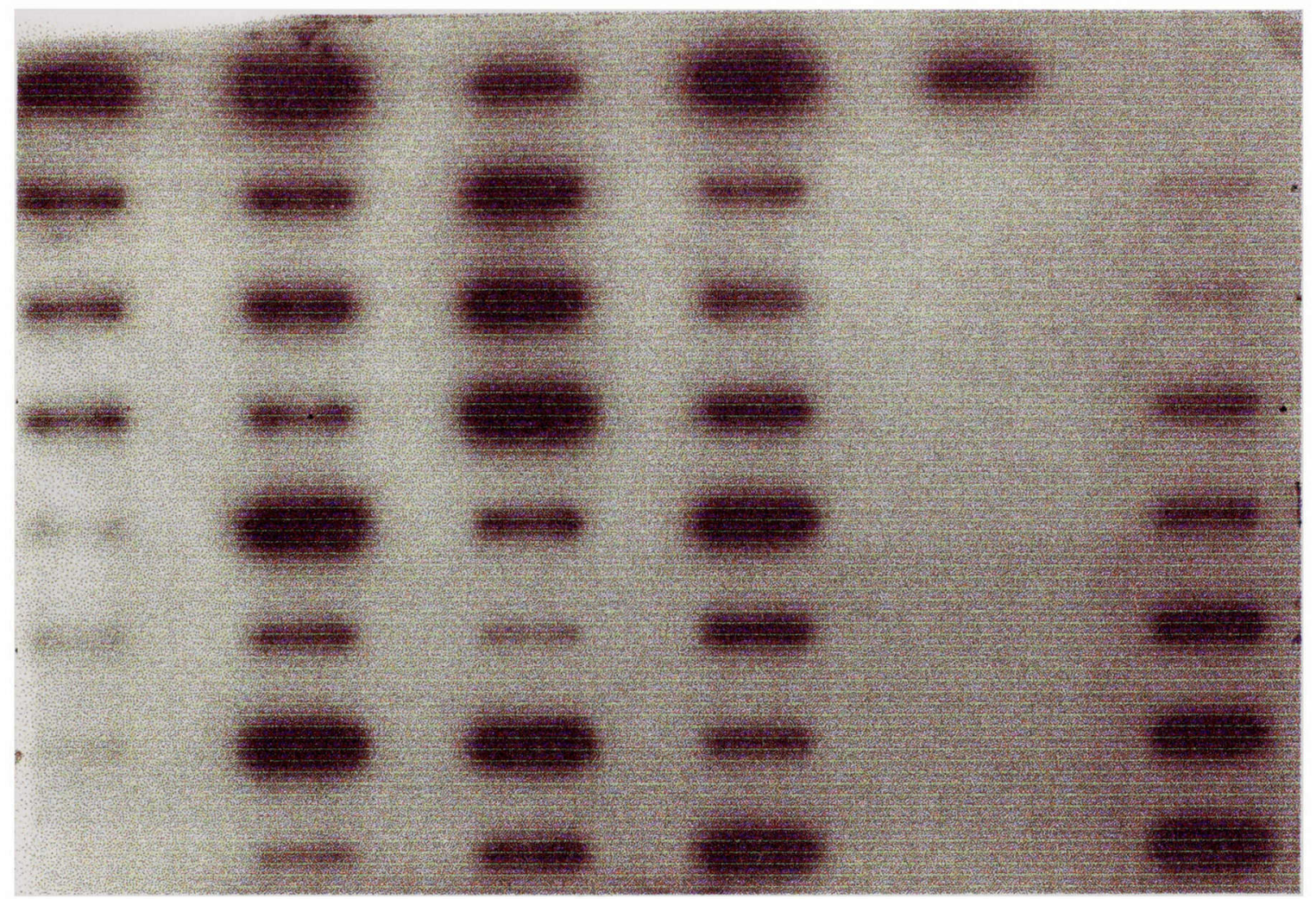

FIGURE 2:Scan of autoradiogram of Slot Blot for DNA sample quantitation. Lanes 1 and 6 standards in ng of DNA:10, $5,2.5,1.25, .625, .313, .156$ in opposite order. Lanes 2-5 contain samples. 


\section{APPENDIX VI}

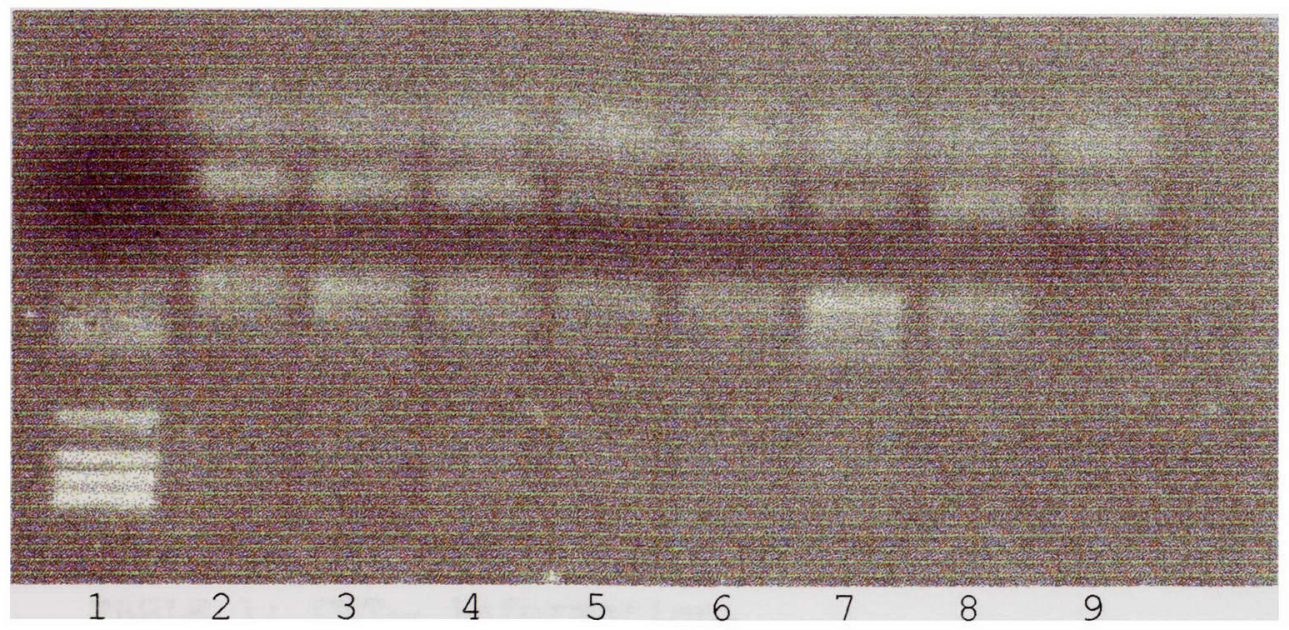

FIGURE 3: Scan polaroid of product gel. Lane 1 contains

size marker $\varphi \chi 174$. Lanes 2-8 contain samples. Lanes 9 contains negative control. All samples amplified. 
APPENDIX VII

\begin{tabular}{|c|c|c|c|c|c|}
\hline STR & $\begin{array}{l}\text { CORE } \\
\text { REPEAT }\end{array}$ & $\begin{array}{l}\text { \# OF CORE } \\
\text { REPEATS }\end{array}$ & $\begin{array}{l}\text { CHROMO- } \\
\text { SOME SITE }\end{array}$ & $\begin{array}{l}\text { CHROMO- } \\
\text { SOME } \\
\text { LOCATION }\end{array}$ & $\begin{array}{l}\text { ALLELIC } \\
\text { LADDER } \\
\text { RANGE } \\
\text { (bp) }\end{array}$ \\
\hline CSF1PO & AGAT & $7-15$ & $\begin{array}{c}\text { CSE-1 } \\
\text { RECEPTOR } \\
\text { GENE }\end{array}$ & 5 & $299-323$ \\
\hline TPOX & AATG & $6-13$ & $\begin{array}{l}\text { THYROID } \\
\text { PEROXID- } \\
\text { ASE GENE }\end{array}$ & 2 & $232-248$ \\
\hline THO1 & AATG & $5-11$ & $\begin{array}{l}\text { TYROSINE } \\
\text { HYDROXY- } \\
\text { LASE GENE }\end{array}$ & 11 & $179-203$ \\
\hline
\end{tabular}

TABLE 1: CTT TM $_{T M}$ Information. 
ALLELE FREQUENCIES FOR CSF

\begin{tabular}{|l|l|l|l|l|l|}
\hline CSF & BW & BB & BAH & JAM & TRI \\
\hline 15 & 2 & 0 & 1 & 0 & 0 \\
\hline 14 & 1 & 2 & 0 & 1 & 1 \\
\hline 13 & 4 & 7 & 8 & 9 & 7 \\
\hline 12 & 44 & 33 & 37 & 26 & 34 \\
\hline 11 & 40 & 22 & 35 & 26 & 23 \\
\hline 10 & 24 & 37 & 25 & 29 & 32 \\
\hline 9 & 5 & 8 & 2 & 8 & 3 \\
\hline 8 & 0 & 6 & 5 & 10 & 14 \\
\hline 7 & 0 & 5 & 7 & 11 & 6 \\
\hline
\end{tabular}

ALLELE FREQUENCIES FOR TPOX

\begin{tabular}{|l|l|l|l|l|l|}
\hline TPOX & BW & BB & BAH & JAM & TRI \\
\hline 13 & 0 & 0 & 1 & 0 & 1 \\
\hline 12 & 4 & 5 & 4 & 4 & 6 \\
\hline 11 & 30 & 25 & 32 & 23 & 32 \\
\hline 10 & 11 & 13 & 12 & 10 & 12 \\
\hline 9 & 16 & 20 & 31 & 36 & 18 \\
\hline 8 & 59 & 44 & 22 & 37 & 41 \\
\hline 7 & 0 & 7 & 4 & 1 & 2 \\
\hline 6 & 0 & 6 & 14 & 9 & 8 \\
\hline
\end{tabular}

ALLELE FREQUENCIES FOR THO1

\begin{tabular}{|l|l|l|l|l|l|}
\hline THO1 & BW & BB & BAH & JAM & TRI \\
\hline 11 & 0 & 0 & 0 & 0 & 0 \\
\hline 10 & 3 & 0 & 2 & 2 & 2 \\
\hline 9.3 & 28 & 9 & 10 & 4 & 5 \\
\hline 9 & 19 & 18 & 17 & 14 & 20 \\
\hline 8 & 17 & 27 & 31 & 27 & 28 \\
\hline 7 & 31 & 47 & 48 & 52 & 41 \\
\hline 6 & 22 & 19 & 12 & 21 & 24 \\
\hline 5 & 0 & 0 & 0 & 0 & 0 \\
\hline
\end{tabular}




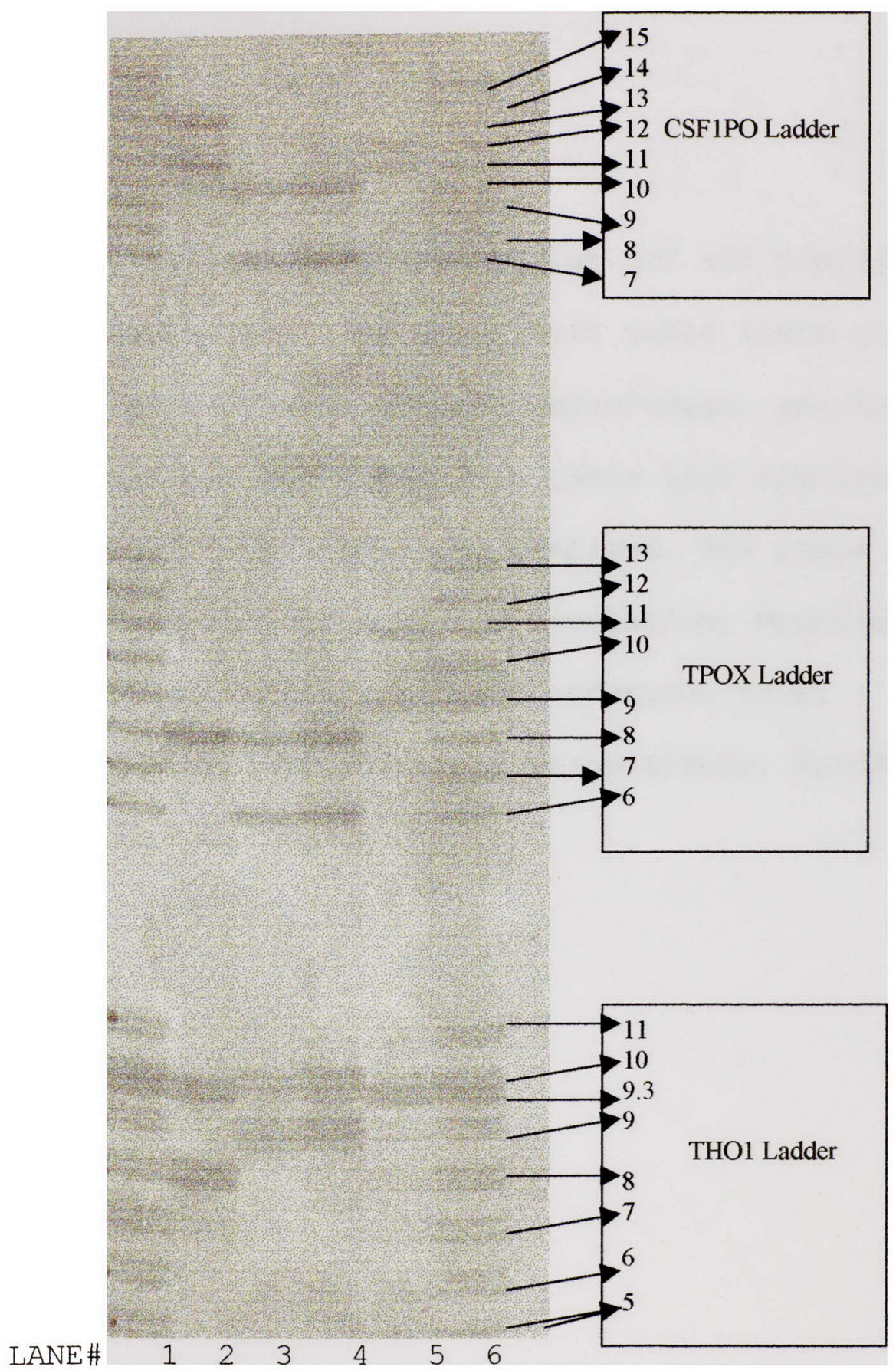

FIGURE 4 : Scan of 6\% Long Ranger gel autoradiogram. Lane \# 1 and 6 contain ladders. Lanes 2-5 contain samples. 


\section{APPENDIX X}

Pages 59-88 : Effect of Substructuring for all populations for all three STR loci. The upper left table lists alleles, frequencies, percentages, squared percentages, and totals for the population. The upper left table list similar data for the population that is being compared. The lower left table is the theoretical combined population. $\mathrm{H}_{\mathrm{T}}$ and $\mathrm{H}_{\mathrm{S}}$ are heterozygosity estimates for the theoretical total population and the subpopulations respectively. $F_{S T}=\left(H_{T}-\right.$ $\left.\mathrm{H}_{S}\right) / \mathrm{H}_{\mathrm{T}}$. 


\begin{tabular}{|c|c|c|c|}
\hline $\begin{array}{r}\text { CSF } \\
=120\end{array}$ & BW & $\mathrm{F}$ of $\mathrm{BW}$ & F2 \\
\hline 15 & 2 & 0.016666 & $2.77778 \mathrm{E}$ \\
\hline 14 & 1 & 0.008333 & $6.94444 \mathrm{E}$ \\
\hline 13 & 4 & 0.033333 & 0.0011111 \\
\hline 12 & 44 & 0.366666 & 0.1344444 \\
\hline 11 & 40 & 0.333333 & 0.1111111 \\
\hline 10 & 24 & 0.2 & \\
\hline 9 & 5 & 0.041666 & 0.0017361 \\
\hline 8 & 0 & 0 & \\
\hline 7 & 0 & 0 & \\
\hline & 120 & 1 & 0.288 \\
\hline CSF & & & \\
\hline $\begin{array}{r}\mathrm{H}_{\mathrm{s}} \\
\text { ues }\end{array}$ & $\mathrm{BW}$ & BB & \\
\hline & 0.71125 & 0.783333 & \\
\hline CSF & $F \quad B W+B B$ & $F / 240$ & $\mathrm{~F} 2(\mathrm{BW}+\mathrm{B}$ \\
\hline 15 & 2 & 0.008333 & \\
\hline 14 & 3 & 0.0125 & 0.000156 \\
\hline 13 & 11 & 0.045833 & 0.0021006 \\
\hline 12 & 77 & 0.320833 & 0.1029340 \\
\hline 11 & 62 & 0.258333 & 0.0667361 \\
\hline 10 & 61 & 0.254166 & 0.0646006 \\
\hline 9 & 13 & 0.054166 & 0.0029340 \\
\hline 8 & 6 & 0.025 & 0.000 \\
\hline 7 & 5 & 0.020833 & $4.34028 \mathrm{E}-$ \\
\hline & 240 & 1 & 1.2405208 \\
\hline & $\mathrm{Ht}=$ & 0.759 & \\
\hline & $\mathrm{Hs}=$ & 0.747291 & \\
\hline & Fst $=$ & 0.015425 & \\
\hline
\end{tabular}




CSF
15
14
13
12
11
10
9
8
7

$\begin{array}{rl}\text { BW } & \text { F } \\ 2 & 0.016666 \\ 1 & 0.008333 \\ 4 & 0.033333 \\ 44 & 0.366666 \\ 40 & 0.333333 \\ 24 & 0.2 \\ 5 & 0.041666 \\ 0 & 0 \\ 0 & 0 \\ 120 & 1\end{array}$

F2 BW

2. $77778 \mathrm{E}-04$

$6.94444 \mathrm{E}-05$

0.001111111

0.134444444

0.111111111

0.04

0.001736111

0
0
0.28875

CSE

$\mathrm{Hs}$

values
0.71125
5.766527

BW $\mathrm{BAH}$

\begin{tabular}{|c|c|c|c|}
\hline SF & $\mathrm{BW}+\mathrm{BAH}$ & $F \quad B W+B A H$ & $\mathrm{~F} 2 \quad \mathrm{BW}+\mathrm{E}$ \\
\hline 15 & 3 & 0.0125 & 0.0001562 \\
\hline 14 & 1 & 0.004166 & $1.73611 \mathrm{E}$ \\
\hline 13 & 12 & 0.05 & 0.0 \\
\hline 12 & 81 & 0.3375 & 0.1139 \\
\hline & 75 & 0.3125 & 0.09765 \\
\hline & 49 & 0.204166 & 0.041684 \\
\hline 9 & 7 & 0.029166 & $8.50694 \mathrm{E}$ \\
\hline 8 & 5 & 0.020833 & $4.34028 \mathrm{E}$ \\
\hline r & 7 & 0.029166 & 8.50694 \\
\hline & 240 & 1 & 0.25 \\
\hline
\end{tabular}

$\mathrm{Ht}=0.741944$

$\mathrm{Hs}=0.738888$

Fst $=0.004118$

$\begin{array}{rll}\text { BAH } & \text { F BAH } & \text { F2 BAH } \\ 1 & 0.008333333 & 6.94444 \mathrm{E}-05 \\ 0 & 0 & 0 \\ 8 & 0.066666667 & 0.004444444 \\ 37 & 0.308333333 & 0.095069444 \\ 35 & 0.291666667 & 0.085069444 \\ 25 & 0.208333333 & 0.043402778 \\ 2 & 0.016666667 & 2.77778 \mathrm{E}-04 \\ 5 & 0.041666667 & 0.001736111 \\ 7 & 0.058333333 & 0.003402778 \\ 120 & 1 & 0.233472222\end{array}$

1

0.258055556 


\begin{tabular}{|c|c|c|c|}
\hline$S F$ & $\mathrm{BW}$ & $\mathrm{F} \quad \mathrm{BW}$ & F2 BW \\
\hline 15 & 2 & 0.016666 & $2.77778 \mathrm{E}-04$ \\
\hline 14 & 1 & 0.008333 & $6.94444 \mathrm{E}-05$ \\
\hline 13 & 4 & 0.033333 & 0.001111111 \\
\hline 12 & 44 & 0.366666 & 0.134444444 \\
\hline 11 & 40 & 0.333333 & 0.111111111 \\
\hline 10 & 24 & 0.2 & 0.04 \\
\hline 9 & 5 & 0.041666 & 0.001736111 \\
\hline 8 & 0 & 0 & 0 \\
\hline 7 & 0 & 0 & 0 \\
\hline & 120 & 1 & 0.28875 \\
\hline CSF & BW & JAM & \\
\hline $\mathrm{HS}$ & 0.71125 & 0.822222 & \\
\hline values & & & \\
\hline CSF & $F \quad B W+J A$ & $F / 240$ & F2 \\
\hline 15 & 2 & 0.008333 & $6.94444 \mathrm{E}-05$ \\
\hline 14 & 2 & 0.008333 & $6.94444 \mathrm{E}-05$ \\
\hline 13 & 13 & 0.054166 & 0.002934028 \\
\hline 12 & 70 & 0.291666 & 0.085069444 \\
\hline 11 & 66 & 0.275 & 0.075625 \\
\hline 10 & 53 & 0.220833 & 0.048767361 \\
\hline 9 & 13 & 0.054166 & 0.002934028 \\
\hline 8 & 10 & 0.041666 & 0.001736111 \\
\hline 7 & 11 & 0.045833 & 0.002100694 \\
\hline & 240 & 1 & 0.219305556 \\
\hline$H t=$ & 0.780694 & & \\
\hline $\mathrm{Hs}=$ & 0.766736 & & \\
\hline Fst $=$ & 0.017879 & & \\
\hline
\end{tabular}




CSF
15
14
13
12
11
10
9
8
7

$\begin{array}{rr}\text { BW } & \text { F BW } \\ 2 & 0.016666 \\ 1 & 0.008333 \\ 4 & 0.033333 \\ 44 & 0.366666 \\ 40 & 0.333333 \\ 24 & 0.2 \\ 5 & 0.041666 \\ 0 & 0 \\ 0 & 0 \\ 120 & 1\end{array}$

CSF

$\begin{array}{rrr}\text { Hs } & \text { BW } & \text { TRI } \\ \text { values } & & \\ & 0.71125 & 0.791666\end{array}$

$\begin{array}{rrrr}\text { CSF } & \text { BW+TRI } & F & \text { F2 } \\ 15 & 2 & 0.008333 & 6.94444 \mathrm{E}-05 \\ 14 & 2 & 0.008333 & 6.94444 \mathrm{E}-05 \\ 13 & 11 & 0.045833 & 0.002100694 \\ 12 & 78 & 0.325 & 0.105625 \\ 11 & 63 & 0.2625 & 0.06890625 \\ 10 & 56 & 0.233333 & 0.054444444 \\ 9 & 8 & 0.033333 & 0.001111111 \\ 8 & 14 & 0.058333 & 0.003402778 \\ 7 & 6 & 0.025 & 0.000625 \\ & 240 & 1 & 0.236354167\end{array}$

$\mathrm{Ht}=0.763645$

$\mathrm{Hs}=0.751458$

Fst $=0.015959$

列

RI

$\begin{array}{rrr}\text { TRI } & \text { F TRI } & \text { F2 TRI } \\ 0 & 0 & 0 \\ 1 & 0.008333333 & 6.94444 \mathrm{E}-05 \\ 7 & 0.058333333 & 0.003402778 \\ 34 & 0.283333333 & 0.080277778 \\ 23 & 0.191666667 & 0.036736111 \\ 32 & 0.266666667 & 0.07111111 \\ 3 & 0.025 & 0.000625 \\ 14 & 0.116666667 & 0.013611111 \\ 6 & 0.05 & 0.0025 \\ 120 & 1 & 0.208333333\end{array}$

2. $77778 \mathrm{E}-04$

$6.94444 \mathrm{E}-05$

0.001111111

0.134444444

0.111111111

0.04

0.001736111

0.28875 


$\begin{array}{rrrrrrr}\text { CFS } & \text { BB } & \text { F BB } & \text { F2 BB } & \text { BAH } & \text { F BAH } & \text { F2 BAH } \\ 15 & 0 & 0 & 0 & 1 & 0.008333333 & 6.94444 \mathrm{E}-05 \\ 14 & 2 & 0.016666 & 2.77778 \mathrm{E}-04 & 0 & 0 & 0 \\ 13 & 7 & 0.058333 & 0.003402778 & 8 & 0.066666667 & 0.004444444 \\ 12 & 33 & 0.275 & 0.075625 & 37 & 0.308333333 & 0.095069444 \\ 11 & 22 & 0.183333 & 0.033611111 & 35 & 0.291666667 & 0.085069444 \\ 10 & 37 & 0.308333 & 0.095069444 & 25 & 0.208333333 & 0.043402778 \\ 9 & 8 & 0.066666 & 0.004444444 & 2 & 0.016666667 & 2.77778 \mathrm{E}-04 \\ 8 & 6 & 0.05 & 0.0025 & 5 & 0.041666667 & 0.001736111 \\ 7 & 5 & 0.041666 & 0.001736111 & 7 & 0.058333333 & 0.003402778 \\ & 120 & 1 & 0.216666667 & 120 & 1 & 0.233472222\end{array}$

$\begin{array}{rrrr}\begin{array}{r}\text { CSF } \\ \text { Hs }\end{array} & \text { BB } & \text { BAH } \\ \text { Values } & & & \\ & 0.783333 & 0.766527 & \\ & & & \\ \text { CSF } & \text { BB+BAH } & \mathrm{F} & \mathrm{F} 2 \\ 15 & 1 & 0.004166 & 1.73611 \mathrm{E}-05 \\ 14 & 2 & 0.008333 & 6.94444 \mathrm{E}-05 \\ 13 & 15 & 0.0625 & 0.00390625 \\ 12 & 70 & 0.291666 & 0.085069444 \\ 11 & 57 & 0.2375 & 0.05640625 \\ 10 & 62 & 0.258333 & 0.066736111 \\ 9 & 10 & 0.041666 & 0.001736111 \\ 8 & 11 & 0.045833 & 0.002100694 \\ 7 & 12 & 0.05 & 0.0025 \\ & 240 & 1 & 0.218541667\end{array}$

$\mathrm{Ht}=0.781458$

$\mathrm{Hs}=0.774930$

Fst $=0.008353$ 


$\begin{array}{rrrrrrr}\text { CFS } & \text { BB } & \text { F BB } & \text { F2 BB } & \text { JAM } & \text { F JAM } & \text { F2 JAM } \\ 15 & 0 & 0 & 0 & 0 & 0 & 0 \\ 14 & 2 & 0.016666 & 2.77778 \mathrm{E}-04 & 1 & 0.008333333 & 6.94444 \mathrm{E}-05 \\ 13 & 7 & 0.058333 & 0.003402778 & 9 & 0.075 & 0.005625 \\ 12 & 33 & 0.275 & 0.075625 & 26 & 0.216666667 & 0.046944444 \\ 11 & 22 & 0.183333 & 0.033611111 & 26 & 0.216666667 & 0.046944444 \\ 10 & 37 & 0.308333 & 0.095069444 & 29 & 0.241666667 & 0.058402778 \\ 9 & 8 & 0.066666 & 0.004444444 & 8 & 0.066666667 & 0.004444444 \\ 8 & 6 & 0.05 & 0.0025 & 10 & 0.083333333 & 0.006944444 \\ 7 & 5 & 0.041666 & 0.001736111 & 11 & 0.091666667 & 0.008402778 \\ & 120 & 1 & 0.216666667 & 120 & 1 & 0.177777778\end{array}$

$\begin{array}{rrrr}\begin{array}{r}\text { CSF } \\ \text { HS }\end{array} & \text { BB } & \text { JAM } & \\ \text { values } & & & \\ & 0.783333 & 0.822222 & \\ & & & \\ \text { CSF } & \text { BB+JAM } & F & 0 \\ 15 & 0 & 0 & 0 \\ 14 & 3 & 0.0125 & 0.00015625 \\ 13 & 16 & 0.066666 & 0.004444444 \\ 12 & 59 & 0.245833 & 0.060434028 \\ 11 & 48 & 0.2 & 0.04 \\ 10 & 66 & 0.275 & 0.075625 \\ 9 & 16 & 0.066666 & 0.004444444 \\ 8 & 16 & 0.066666 & 0.004444444 \\ 7 & 16 & 0.066666 & 0.004444444 \\ & 240 & 1 & 0.193993056\end{array}$

$\mathrm{H} t=0.806006$

$\mathrm{Hs}=0.802777$

Fst $=0.004006$ 


$\begin{array}{rrrrrrr}\text { CSF } & \text { BB } & \text { F BB } & \text { F2 BB } & \text { TRI } & \text { F TRI } & \text { F2 TRI } \\ 15 & 0 & 0 & 0 & 0 & 0 & 0 \\ 14 & 2 & 0.016666 & 2.77778 \mathrm{E}-04 & 1 & 0.008333333 & 6.94444 \mathrm{E}-05 \\ 13 & 7 & 0.058333 & 0.003402778 & 7 & 0.058333333 & 0.003402778 \\ 12 & 33 & 0.275 & 0.075625 & 34 & 0.283333333 & 0.080277778 \\ 11 & 22 & 0.183333 & 0.033611111 & 23 & 0.191666667 & 0.036736111 \\ 10 & 37 & 0.308333 & 0.095069444 & 32 & 0.266666667 & 0.07111111 \\ 9 & 8 & 0.066666 & 0.004444444 & 3 & 0.025 & 0.000625 \\ 8 & 6 & 0.05 & 0.0025 & 14 & 0.116666667 & 0.013611111 \\ 7 & 5 & 0.041666 & 0.001736111 & 6 & 0.05 & 0.0025 \\ & 120 & 1 & 0.216666667 & 120 & 1 & 0.20833333\end{array}$

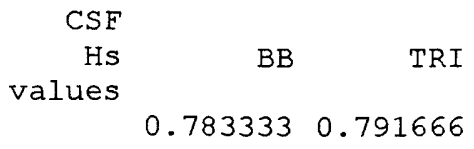

$\begin{array}{rrrr}\text { CSF } & \text { BB+TRI } & F & \text { F2 } \\ 15 & 0 & 0 & 0 \\ 14 & 3 & 0.0125 & 0.00015625 \\ 13 & 14 & 0.058333 & 0.003402778 \\ 12 & 67 & 0.279166 & 0.077934028 \\ 11 & 45 & 0.1875 & 0.03515625 \\ 10 & 69 & 0.2875 & 0.08265625 \\ 9 & 11 & 0.045833 & 0.002100694 \\ 8 & 20 & 0.083333 & 0.006944444 \\ 7 & 11 & 0.045833 & 0.002100694 \\ & 240 & 1 & 0.210451389\end{array}$

$\mathrm{H} t=0.789548$

$\mathrm{Hs}=0.7875$

Fst $=0.002594$ 


$\begin{array}{rrrrrrr}\text { CSF } & \text { BAH } & \text { F BAH } & \text { F2 BAH } & \text { JAM } & \text { F JAM } & \text { F2 JAM } \\ 15 & 1 & 0.008333 & 6.94444 \mathrm{E}-05 & 0 & 0 & 0 \\ 14 & 0 & 0 & 0 & 1 & 0.008333333 & 6.94444 \mathrm{E}-05 \\ 13 & 8 & 0.066666 & 0.004444444 & 9 & 0.075 & 0.005625 \\ 12 & 37 & 0.308333 & 0.095069444 & 26 & 0.216666667 & 0.046944444 \\ 11 & 35 & 0.291666 & 0.085069444 & 26 & 0.216666667 & 0.046944444 \\ 10 & 25 & 0.208333 & 0.043402778 & 29 & 0.241666667 & 0.058402778 \\ 9 & 2 & 0.016666 & 2.77778 \mathrm{E}-04 & 8 & 0.066666667 & 0.004444444 \\ 8 & 5 & 0.041666 & 0.001736111 & 10 & 0.083333333 & 0.006944444 \\ 7 & 7 & 0.058333 & 0.003402778 & 11 & 0.091666667 & 0.008402778 \\ & 120 & 1 & 0.233472222 & 120 & 1 & 0.177777778\end{array}$

$\begin{array}{rrr}\text { CSF } & & \\ \text { Hs } & \text { BAH } & \text { JAM } \\ \text { values } & & \\ & 0.766527 & 0.822222\end{array}$

$\begin{array}{rrrr}\text { CSF } & \text { BAH+JAM } & F & F 2 \\ 15 & 1 & 0.004166 & 1.73611 \mathrm{E}-05 \\ 14 & 1 & 0.004166 & 1.73611 \mathrm{E}-05 \\ 13 & 17 & 0.070833 & 0.005017361 \\ 12 & 63 & 0.2625 & 0.06890625 \\ 11 & 61 & 0.254166 & 0.064600694 \\ 10 & 54 & 0.225 & 0.050625 \\ 9 & 10 & 0.041666 & 0.001736111 \\ 8 & 15 & 0.0625 & 0.00390625 \\ 7 & 18 & 0.075 & 0.005625 \\ & 240 & 1 & 0.200451389\end{array}$

$\mathrm{H} t=0.799548$

$\mathrm{Hs}=0.794375$

F'st $=0.006470$ 


CSF
15
14
13
12
11
10
9
8
7

$\begin{array}{rrr}\mathrm{BAH} & \mathrm{F} \text { BAH } & \mathrm{F} 2 \mathrm{BAH} \\ 1 & 0.008333 & 6.94444 \mathrm{E}-05 \\ 0 & 0 & 0 \\ 8 & 0.066666 & 0.004444444 \\ 37 & 0.308333 & 0.095069444 \\ 35 & 0.291666 & 0.085069444 \\ 25 & 0.208333 & 0.043402778 \\ 2 & 0.016666 & 2.77778 \mathrm{E}-04 \\ 5 & 0.041666 & 0.001736111 \\ 7 & 0.058333 & 0.003402778 \\ 120 & 1 & 0.233472222\end{array}$

$\begin{array}{rrr}\text { TRI } & \text { F TRI } & \text { F2 TRI } \\ 0 & 0 & 0 \\ 1 & 0.008333333 & 6.94444 \mathrm{E}-05 \\ 7 & 0.058333333 & 0.003402778 \\ 34 & 0.283333333 & 0.080277778 \\ 23 & 0.191666667 & 0.036736111 \\ 32 & 0.266666667 & 0.071111111 \\ 3 & 0.025 & 0.000625 \\ 14 & 0.116666667 & 0.013611111 \\ 6 & 0.05 & 0.0025 \\ 120 & 1 & 0.208333333\end{array}$

$\begin{array}{rr}\text { CSF } & \\ \text { Hs value } & \text { BAH } \\ & 0.766527 \\ \text { CSF } & \text { BAH+TRI } \\ 15 & 1 \\ 14 & 1 \\ 13 & 15 \\ 12 & 71 \\ 11 & 58 \\ 10 & 57 \\ 9 & 5 \\ 8 & 19 \\ 7 & 13 \\ & 240 \\ \text { Ht }= & 0.784097 \\ \text { Hs }= & 0.779097 \\ \text { Fst }= & 0.006376\end{array}$




$\begin{array}{rrrrrrr}\text { CSF } & \text { JAM } & \text { F JAM } & \text { F2 JAM } & \text { TRI } & \text { F TRI } & \text { F2 TRI } \\ 15 & 0 & 0 & 0 & 0 & 0 & 0 \\ 14 & 1 & 0.008333 & 6.94444 \mathrm{E}-05 & 1 & 0.008333333 & 6.94444 \mathrm{E}-05 \\ 13 & 9 & 0.075 & 0.005625 & 7 & 0.058333333 & 0.003402778 \\ 12 & 26 & 0.216666 & 0.046944444 & 34 & 0.283333333 & 0.080277778 \\ 11 & 26 & 0.216666 & 0.046944444 & 23 & 0.191666667 & 0.036736111 \\ 10 & 29 & 0.241666 & 0.058402778 & 32 & 0.266666667 & 0.07111111 \\ 9 & 8 & 0.066666 & 0.004444444 & 3 & 0.025 & 0.000625 \\ 8 & 10 & 0.083333 & 0.006944444 & 14 & 0.116666667 & 0.013611111 \\ 7 & 11 & 0.091666 & 0.008402778 & 6 & 0.05 & 0.0025 \\ & 120 & 1 & 0.177777778 & 120 & 1 & 0.208333333\end{array}$

$\begin{array}{rrrr}\begin{array}{r}\text { CFS } \\ \text { Hs Value }\end{array} & \begin{array}{r}\text { JAM } \\ \text { TRI }\end{array} \\ & & & \\ \text { CSF } & \text { JAM+TRI } & F & \text { F2 } \\ 15 & 0 & 0 & 0 \\ 14 & 2 & 0.008333 & 6.94444 \mathrm{E}-05 \\ 13 & 16 & 0.066666 & 0.004444444 \\ 12 & 60 & 0.25 & 0.0625 \\ 11 & 49 & 0.204166 & 0.041684028 \\ 10 & 61 & 0.254166 & 0.064600694 \\ 9 & 11 & 0.045833 & 0.002100694 \\ 8 & 24 & 0.1 & 0.01 \\ 7 & 17 & 0.070833 & 0.005017361 \\ & 240 & 1 & 0.190416667 \\ \text { Ht }= & 0.809583 & & \\ \text { Hs }= & 0.806944 & & \\ \text { Fst }=0.003259 & & \end{array}$




$\begin{array}{rrrrrrr}\text { TPOX } & \text { BW } & \text { F BW } & \text { F2 BW } & \text { BB } & \text { F BB } & \text { F2 BB } \\ 13 & 0 & 0 & 0 & 0 & 0 & 0 \\ 12 & 4 & 0.033333 & 0.001111111 & 5 & 0.041666667 & 0.001736111 \\ 11 & 30 & 0.25 & 0.0625 & 25 & 0.208333333 & 0.043402778 \\ 10 & 11 & 0.091666 & 0.008402778 & 13 & 0.108333333 & 0.011736111 \\ 9 & 16 & 0.133333 & 0.017777778 & 20 & 0.166666667 & 0.027777778 \\ 8 & 59 & 0.491666 & 0.241736111 & 44 & 0.366666667 & 0.134444444 \\ 7 & 0 & 0 & 0 & 7 & 0.058333333 & 0.003402778 \\ 6 & 0 & 0 & 0 & 6 & 0.05 & 0.0025 \\ & 120 & 1 & 0.331527778 & 120 & 1 & 0.225\end{array}$

TPOX

Hs value
$\mathrm{BW}$
0.668472
$\mathrm{BB}$

TPOX

13

BW+BB $\quad \mathrm{F}$

$\begin{array}{ll}0 & 0\end{array}$

0.0375

$\begin{array}{ll}55 & 0.229166\end{array}$

$24 \quad 0.1$

36

0.15

1030.429166

70.029166

$6 \quad 0.025$

1

F2

0.00140625

0.052517361

0.01

0.0225

0.184184028

8. $50694 \mathrm{E}-04$

0.000625

0.272083333

$\mathrm{H} t=0.727916$

$\mathrm{Hs}=0.721736$

Fst $=0.008490$ 


$\begin{array}{rrrrrrr}\text { TPOX } & \text { BW } & \text { F BW } & \text { F2 BW } & \text { BAH } & \text { F BAH } & \text { F2 BAH } \\ 13 & 0 & 0 & 0 & 1 & 0.008333333 & 6.94444 \mathrm{E}-05 \\ 12 & 4 & 0.033333 & 0.001111111 & 4 & 0.033333333 & 0.00111111 \\ 11 & 30 & 0.25 & 0.0625 & 32 & 0.266666667 & 0.071111111 \\ 10 & 11 & 0.091666 & 0.008402778 & 12 & 0.1 & 0.01 \\ 9 & 16 & 0.133333 & 0.017777778 & 31 & 0.258333333 & 0.066736111 \\ 8 & 59 & 0.491666 & 0.241736111 & 22 & 0.183333333 & 0.033611111 \\ 7 & 0 & 0 & 0 & 4 & 0.033333333 & 0.001111111 \\ 6 & 0 & 0 & 0 & 14 & 0.116666667 & 0.013611111 \\ & 120 & 1 & 0.331527778 & 120 & 1 & 0.197361111\end{array}$

TPOX

$\begin{array}{rrrr}\text { Hs } & \text { BW } & \text { BAH } & \\ \text { Values } & & & \\ & 0.668472 & 0.802638 & \text { F2 } \\ \text { TPOX } & \text { BW+BAH } & F & 1.73611 \mathrm{E}-05 \\ 13 & 1 & 0.004166 & 1.700111111 \\ 12 & 8 & 0.033333 & 0.00111 \\ 11 & 62 & 0.258333 & 0.066736111 \\ 10 & 23 & 0.095833 & 0.009184028 \\ 9 & 47 & 0.195833 & 0.038350694 \\ 8 & 81 & 0.3375 & 0.11390625 \\ 7 & 4 & 0.016666 & 2.77778 \mathrm{E}-04 \\ 6 & 14 & 0.058333 & 0.003402778 \\ & 240 & 1 & 0.232986111\end{array}$

$H t=0.767013$

$\mathrm{Hs}=0.735555$

Fst $=0.041014$ 


$\begin{array}{rrrrrrr}\text { TPOX } & \text { BW } & \text { F BW } & \text { F2 BW } & \text { JAM } & \text { F JAM } & \text { F2 JAM } \\ 13 & 0 & 0 & 0 & 0 & 0 & 0 \\ 12 & 4 & 0.033333 & 0.001111111 & 4 & 0.033333333 & 0.001111111 \\ 11 & 30 & 0.25 & 0.0625 & 23 & 0.191666667 & 0.036736111 \\ 10 & 11 & 0.091666 & 0.008402778 & 10 & 0.083333333 & 0.006944444 \\ 9 & 16 & 0.133333 & 0.017777778 & 36 & 0.3 & 0.09 \\ 8 & 59 & 0.491666 & 0.241736111 & 37 & 0.308333333 & 0.095069444 \\ 7 & 0 & 0 & 0 & 1 & 0.008333333 & 6.94444 \mathrm{E}-05 \\ 6 & 0 & 0 & 0 & 9 & 0.075 & 0.005625 \\ & 120 & 1 & 0.331527778 & 120 & 1 & 0.235555556\end{array}$

TPOX

$\begin{array}{rrr}\text { Hs } & \text { BW } & \text { JAM } \\ \text { Values } & & \\ & 0.668472 & 0.764444\end{array}$

$\begin{array}{rrrr}\text { TPOX } & \text { BW+JAM } & \text { F } & \text { F2 } \\ 13 & 0 & 0 & 0 \\ 12 & 8 & 0.033333 & 0.001111111 \\ 11 & 53 & 0.220833 & 0.048767361 \\ 10 & 21 & 0.0875 & 0.00765625 \\ 9 & 52 & 0.216666 & 0.046944444 \\ 8 & 96 & 0.4 & 0.16 \\ 7 & 1 & 0.004166 & 1.73611 \mathrm{E}-05 \\ 6 & 9 & 0.0375 & 0.00140625 \\ & 240 & 1 & 0.265902778\end{array}$

$H t=0.734097$

$\mathrm{Hs}=0.716458$

Fst $=0.024028$ 


$\begin{array}{rrrrrrr}\text { TPOX } & \text { BW } & \text { F BW } & \text { F2 BW } & \text { TRI } & \text { F TRI } & \text { F2 TRI } \\ 13 & 0 & 0 & 0 & 1 & 0.008333333 & 6.94444 \mathrm{E}-05 \\ 12 & 4 & 0.033333 & 0.001111111 & 6 & 0.05 & 0.0025 \\ 11 & 30 & 0.25 & 0.0625 & 32 & 0.266666667 & 0.071111111 \\ 10 & 11 & 0.091666 & 0.008402778 & 12 & 0.1 & 0.01 \\ 9 & 16 & 0.133333 & 0.017777778 & 18 & 0.15 & 0.0225 \\ 8 & 59 & 0.491666 & 0.241736111 & 41 & 0.341666667 & 0.116736111 \\ 7 & 0 & 0 & 0 & 2 & 0.016666667 & 2.77778 \mathrm{E}-04 \\ 6 & 0 & 0 & 0 & 8 & 0.066666667 & 0.004444444 \\ & 120 & 1 & 0.331527778 & & 1 & 0.227638889\end{array}$

$\begin{array}{rrrr}\text { TPOX } & \text { BW+TRI } & \text { F } & \text { F2 } \\ 13 & 1 & 0.004166 & 1.73611 \mathrm{E}-05 \\ 12 & 10 & 0.041666 & 0.001736111 \\ 11 & 62 & 0.258333 & 0.066736111 \\ 10 & 23 & 0.095833 & 0.009184028 \\ 9 & 34 & 0.141666 & 0.020069444 \\ 8 & 100 & 0.416666 & 0.173611111 \\ 7 & 2 & 0.008333 & 6.94444 \mathrm{E}-05 \\ 6 & 8 & 0.033333 & 0.001111111 \\ & 240 & 1 & 0.272534722\end{array}$

$\mathrm{H} t=0.727465$

Hs $=0.720416$

Fst $=0.009689$ 


$\begin{array}{rrrrrrr}\text { TPOX } & \text { BB } & \text { F BB } & \text { F2 BB } & \text { BAH } & \text { F BAH } & \text { F2 BAH } \\ 13 & 0 & 0 & 0 & 1 & 0.008333333 & 6.94444 \mathrm{E}-05 \\ 12 & 5 & 0.041666 & 0.001736111 & 4 & 0.033333333 & 0.001111111 \\ 11 & 25 & 0.208333 & 0.043402778 & 32 & 0.266666667 & 0.07111111 \\ 10 & 13 & 0.108333 & 0.011736111 & 12 & 0.1 & 0.01 \\ 9 & 20 & 0.166666 & 0.027777778 & 31 & 0.258333333 & 0.066736111 \\ 8 & 44 & 0.366666 & 0.134444444 & 22 & 0.183333333 & 0.033611111 \\ 7 & 7 & 0.058333 & 0.003402778 & 4 & 0.033333333 & 0.001111111 \\ 6 & 6 & 0.05 & 0.0025 & 14 & 0.116666667 & 0.013611111 \\ & 120 & 1 & 0.225 & 120 & 1 & 0.197361111\end{array}$

TPOX

Hs Value
0.775
BB $\mathrm{BAH}$
0.802638

$\begin{array}{rrrr}\text { TPOX } & \text { BB+BAH } & \mathrm{F} & \mathrm{F} 2 \\ 13 & 1 & 0.004166 & 1.73611 \mathrm{E}-05 \\ 12 & 9 & 0.0375 & 0.00140625 \\ 11 & 57 & 0.2375 & 0.05640625 \\ 10 & 25 & 0.104166 & 0.010850694 \\ 9 & 51 & 0.2125 & 0.04515625 \\ 8 & 66 & 0.275 & 0.075625 \\ 7 & 11 & 0.045833 & 0.002100694 \\ 6 & 20 & 0.083333 & 0.006944444 \\ & 240 & 1 & 0.198506944\end{array}$

$\mathrm{H} t=0.801493$

$\mathrm{Hs}=0.788819$

Fst $=0.015812$ 


$\begin{array}{rrrrrrr}\text { TPOX } & \text { BB } & \text { F BB } & \text { F2 BB } & \text { JAM } & \text { F JAM } & \text { F2 JAM } \\ 13 & 0 & 0 & 0 & 0 & 0 & 0 \\ 12 & 5 & 0.041666 & 0.001736111 & 4 & 0.033333333 & 0.001111111 \\ 11 & 25 & 0.208333 & 0.043402778 & 23 & 0.191666667 & 0.036736111 \\ 10 & 13 & 0.108333 & 0.011736111 & 10 & 0.083333333 & 0.006944444 \\ 9 & 20 & 0.166666 & 0.027777778 & 36 & 0.3 & 0.09 \\ 8 & 44 & 0.366666 & 0.134444444 & 37 & 0.308333333 & 0.095069444 \\ 7 & 7 & 0.058333 & 0.003402778 & 1 & 0.008333333 & 6.94444 \mathrm{E}-05 \\ 6 & 6 & 0.05 & 0.0025 & 9 & 0.075 & 0.005625 \\ & 120 & 1 & 0.225 & 120 & 1 & 0.235555556\end{array}$

$\begin{array}{rrrr}\begin{array}{r}\text { TPOX } \\ \text { HS }\end{array} & \text { BB } & \text { JAM } & \\ \text { Values } & & & \\ & 0.775 & 0.764444 & \\ \text { TPOX } & \text { BB+JAM } & F & \text { F2 } \\ 13 & 0 & 0 & 0 \\ 12 & 9 & 0.0375 & 0.00140625 \\ 11 & 48 & 0.2 & 0.04 \\ 10 & 23 & 0.095833 & 0.009184028 \\ 9 & 56 & 0.233333 & 0.054444444 \\ 8 & 81 & 0.3375 & 0.11390625 \\ 7 & 8 & 0.033333 & 0.001111111 \\ 6 & 15 & 0.0625 & 0.00390625 \\ & 240 & 1 & 0.223958333\end{array}$

$\mathrm{H} t=0.776041$

$\mathrm{Hs}=0.769722$

Fst $=0.008143$ 


$\begin{array}{rrrr}\text { TPOX } & \text { BB } & \text { F BB } & \text { F2 BB } \\ 13 & 0 & 0 & 0 \\ 12 & 5 & 0.041666 & 0.001736111 \\ 11 & 25 & 0.208333 & 0.043402778 \\ 10 & 13 & 0.108333 & 0.011736111 \\ 9 & 20 & 0.166666 & 0.027777778 \\ 8 & 44 & 0.366666 & 0.134444444 \\ 7 & 7 & 0.058333 & 0.003402778 \\ 6 & 6 & 0.05 & 0.0025 \\ & 120 & 1 & 0.225\end{array}$

$\begin{array}{rrr}\text { TRI } & \text { F TRI } & \text { F2 TRI } \\ 1 & 0.008333333 & 6.94444 \mathrm{E}-05 \\ 6 & 0.05 & 0.0025 \\ 32 & 0.266666667 & 0.071111111 \\ 12 & 0.1 & 0.01 \\ 18 & 0.15 & 0.0225 \\ 41 & 0.341666667 & 0.116736111 \\ 2 & 0.016666667 & 2.77778 \mathrm{E}-04 \\ 8 & 0.066666667 & 0.004444444 \\ 120 & 1 & 0.227638889\end{array}$

$\begin{array}{rrrr}\text { TPOX } & & \\ \text { Hs } & \text { BB } & \text { TRI } \\ \text { Values } & & \\ & 0.775 & 0.772361\end{array}$

$\begin{array}{rrrr}\text { TPOX } & \text { BB+TRI } & F & \text { F2 } \\ 13 & 1 & 0.004166 & 1.73611 \mathrm{E}-05 \\ 12 & 11 & 0.045833 & 0.002100694 \\ 11 & 57 & 0.2375 & 0.05640625 \\ 10 & 25 & 0.104166 & 0.010850694 \\ 9 & 38 & 0.158333 & 0.025069444 \\ 8 & 85 & 0.354166 & 0.125434028 \\ 7 & 9 & 0.0375 & 0.00140625 \\ 6 & 14 & 0.058333 & 0.003402778 \\ & 240 & 1 & 0.2246875\end{array}$

$\mathrm{H} t=0.775312$

$\mathrm{Hs}=0.773680$

Fst $=0.002104$ 


TPOX
13
12
11
10
9
8
7
6

$\begin{array}{rrr}\mathrm{BAH} & \mathrm{F} \mathrm{BAH} & \mathrm{F} 2 \mathrm{BAH} \\ 1 & 0.008333 & 6.94444 \mathrm{E}-05 \\ 4 & 0.033333 & 0.001111111 \\ 32 & 0.266666 & 0.071111111 \\ 12 & 0.1 & 0.01 \\ 31 & 0.258333 & 0.066736111 \\ 22 & 0.183333 & 0.033611111 \\ 4 & 0.033333 & 0.001111111 \\ 14 & 0.116666 & 0.013611111 \\ 120 & 1 & 0.197361111\end{array}$

JAM
0
4
23
10
36
37
1
9
120

$\begin{array}{rr}\text { F JAM } & \text { F2 JAM } \\ 0 & 0 \\ 0.033333333 & 0.001111111 \\ 0.191666667 & 0.036736111 \\ 0.083333333 & 0.006944444 \\ 0.3 & 0.09 \\ 0.308333333 & 0.095069444 \\ 0.008333333 & 6.94444 \mathrm{E}-05 \\ 0.075 & 0.005625 \\ 1 & 0.235555556\end{array}$

TPOX

Hs Value

$\begin{array}{rr}\text { BAH } & \text { JAM } \\ 0.802638 & 0.764444\end{array}$

$\begin{array}{rrrr}\text { TPOX } & \text { BAH+JAM } & F & F 2 \\ 13 & 1 & 0.004166 & 1.73611 \mathrm{E}-05 \\ 12 & 8 & 0.033333 & 0.001111111 \\ 11 & 55 & 0.229166 & 0.052517361 \\ 10 & 22 & 0.091666 & 0.008402778 \\ 9 & 67 & 0.279166 & 0.077934028 \\ 8 & 59 & 0.245833 & 0.060434028 \\ 7 & 5 & 0.020833 & 4.34028 \mathrm{E}-04 \\ 6 & 23 & 0.095833 & 0.009184028 \\ & 240 & 1 & 0.210034722\end{array}$

$\mathrm{H} t=0.789965$

$\mathrm{Hs}=0.783541$

Fst $=0.008131$ 


$\begin{array}{rrrr}\text { TPOX } & \text { BAH } & \text { F BAH } & \text { F2 BAH } \\ 13 & 1 & 0.008333 & 6.9444 \mathrm{E}-05 \\ 12 & 4 & 0.033333 & 0.001111111 \\ 11 & 32 & 0.266666 & 0.071111111 \\ 10 & 12 & 0.1 & 0.01 \\ 9 & 31 & 0.258333 & 0.066736111 \\ 8 & 22 & 0.183333 & 0.033611111 \\ 7 & 4 & 0.033333 & 0.001111111 \\ 6 & 14 & 0.116666 & 0.013611111 \\ & 120 & 1 & 0.197361111\end{array}$

TRI

1

6

32

12

18

41

2

8

120
F TRI
0.008333333
0.05
0.266666667
0.1
0.15
0.341666667
0.016666667
0.066666667
F2 TRI
$6.94444 \mathrm{E}-05$
0.0025
0.071111111
0.01
0.0225
0.116736111
$2.77778 \mathrm{E}-04$
0.004444444
0.227638889

TPOX

$\mathrm{Hs}$

Values

0.802638

0.772361

TPOX

$\mathrm{BAH}+\mathrm{TRI}$

20.008333

100.041666

$\begin{array}{ll}64 & 0.266666\end{array}$

24

0.1

490.204166

63

0.2625

6

0.025

220.091666

240

1
F2

6. $94444 \mathrm{E}-05$

0.001736111

0.071111111

0.01

0.041684028

0.06890625

0.000625

0.008402778

0.202534722

$\mathrm{H} t=0.797465$

$\mathrm{Hs}=0.7875$

Fst $=0.012496$ 


$\begin{array}{rrrrrrr}\text { TPOX } & \text { JAM } & \text { F JAM } & \text { F2 JAM } & \text { TRI } & \text { F TRI } & \text { F2 TRI } \\ 13 & 0 & 0 & 0 & 1 & 0.008333333 & 6.94444 \mathrm{E}-05 \\ 12 & 4 & 0.033333 & 0.001111111 & 6 & 0.05 & 0.0025 \\ 11 & 23 & 0.191666 & 0.036736111 & 32 & 0.266666667 & 0.071111111 \\ 10 & 10 & 0.083333 & 0.006944444 & 12 & 0.1 & 0.01 \\ 9 & 36 & 0.3 & 0.09 & 18 & 0.15 & 0.0225 \\ 8 & 37 & 0.308333 & 0.095069444 & 41 & 0.341666667 & 0.116736111 \\ 7 & 1 & 0.008333 & 6.94444 \mathrm{E}-05 & 2 & 0.016666667 & 2.77778 \mathrm{E}-04 \\ 6 & 9 & 0.075 & 0.005625 & 8 & 0.066666667 & 0.004444444 \\ & 120 & 1 & 0.235555556 & 120 & 1 & 0.227638889\end{array}$

TPOX

Hs

JAM TRI

Values

$0.764444 \quad 0.772361$

$\begin{array}{rrrr}\text { TPOX } & \text { JAM+TRI } & \text { F } & \text { F2 } \\ 13 & 1 & 0.004166 & 1.73611 \mathrm{E}-05 \\ 12 & 10 & 0.041666 & 0.001736111 \\ 11 & 55 & 0.229166 & 0.052517361 \\ 10 & 22 & 0.091666 & 0.008402778 \\ 9 & 54 & 0.225 & 0.050625 \\ 8 & 78 & 0.325 & 0.105625 \\ 7 & 3 & 0.0125 & 0.00015625 \\ 6 & 17 & 0.070833 & 0.005017361 \\ & 240 & 1 & 0.224097222\end{array}$

$\mathrm{H} t=0.775902$

$\mathrm{Hs}=0.768402$

Fst $=0.009666$ 


$\begin{array}{rrrrrrr}\text { THOI } & \text { BW } & \text { F BW } & \text { F2 BW } & \text { BB } & \text { F BB } & \text { F2 BB } \\ 11 & 0 & 0 & 0 & 0 & 0 & 0 \\ 10 & 3 & 0.025 & 0.000625 & 0 & 0 & 0 \\ 9.3 & 28 & 0.233333 & 0.054444444 & 9 & 0.075 & 0.005625 \\ 9 & 19 & 0.158333 & 0.025069444 & 18 & 0.15 & 0.0225 \\ 8 & 17 & 0.141666 & 0.020069444 & 27 & 0.225 & 0.050625 \\ 7 & 31 & 0.258333 & 0.066736111 & 47 & 0.391666667 & 0.153402778 \\ 6 & 22 & 0.183333 & 0.033611111 & 19 & 0.158333333 & 0.025069444 \\ 5 & 0 & 0 & 0 & 0 & 0 & 0 \\ & 120 & 1 & 0.200555556 & 120 & 1 & 0.257222222\end{array}$

THOI

$\begin{array}{rrrr}\text { Hs } & \text { BW } & \text { BB } \\ \text { Values } & & & \\ & 0.799444 & 0.742777 & \\ \text { THOI } & \text { BW+BB } & F & \text { F2 } \\ 11 & 0 & 0 & 0 \\ 10 & 3 & 0.0125 & 0.00015625 \\ 9.3 & 37 & 0.154166 & 0.023767361 \\ 9 & 37 & 0.154166 & 0.023767361 \\ 8 & 44 & 0.183333 & 0.033611111 \\ 7 & 78 & 0.325 & 0.105625 \\ 6 & 41 & 0.170833 & 0.029184028 \\ 5 & 0 & 0 & 0 \\ & 240 & 1 & 0.216111111\end{array}$

$\mathrm{H} t=0.783888$

$\mathrm{Hs}=0.771111$

Fst $=0.016300$ 


$\begin{array}{rrrr}\text { THOI } & \text { BW } & \text { F BW } & \text { F2 BW } \\ 11 & 0 & 0 & 0 \\ 10 & 3 & 0.025 & 0.000625 \\ 9.3 & 28 & 0.233333 & 0.054444444 \\ 9 & 19 & 0.158333 & 0.025069444 \\ 8 & 17 & 0.141666 & 0.020069444 \\ 7 & 31 & 0.258333 & 0.066736111 \\ 6 & 22 & 0.183333 & 0.033611111 \\ 5 & 0 & 0 & 0 \\ & 120 & 1 & 0.200555556 \\ \text { THO1 } & & & \\ \text { Hs } & 0.799444 & 0.735972 & \\ \text { Values } & & & \\ & & & \\ \text { THO1 } & \text { BW+BAH } & F & 0 \\ 11 & 0 & 0 & \\ 10 & 5 & 0.020833 & 4.34028 \mathrm{E}-04 \\ 9.3 & 38 & 0.158333 & 0.025069444 \\ 9 & 36 & 0.15 & 0.0225 \\ 8 & 48 & 0.2 & 0.04 \\ 7 & 79 & 0.329166 & 0.108350694 \\ 6 & 34 & 0.141666 & 0.020069444 \\ 5 & 0 & 0 & 0 \\ & 240 & 1 & 0.216423611\end{array}$

$\mathrm{H} t=0.783576$

$\mathrm{Hs}=0.767708$

Fst $=0.020250$ 


$\begin{array}{rrrrrrr}\text { THOI } & \text { BW } & \text { F BW } & \text { F2 BW } & \text { JAM } & \text { F JAM } & \text { F2 JAM } \\ 11 & 0 & 0 & 0 & 0 & 0 & 0 \\ 10 & 3 & 0.025 & 0.000625 & 2 & 0.016666667 & 2.77778 \mathrm{E}-04 \\ 9.3 & 28 & 0.233333 & 0.054444444 & 4 & 0.033333333 & 0.001111111 \\ 9 & 19 & 0.158333 & 0.025069444 & 14 & 0.116666667 & 0.013611111 \\ 8 & 17 & 0.141666 & 0.020069444 & 27 & 0.225 & 0.050625 \\ 7 & 31 & 0.258333 & 0.066736111 & 52 & 0.433333333 & 0.187777778 \\ 6 & 22 & 0.183333 & 0.033611111 & 0.030625 \\ 5 & 0 & 0 & 0 & 0 & 0.175 & 0.030625 \\ & 120 & 1 & 0.200555556 & 120 & 0 & 0 \\ & & & & & 1 & 0.284027778\end{array}$

THOI

HsValues

$\begin{array}{rr}\text { BW } & \text { JAM } \\ 0.799444 & 0.715972\end{array}$

$\begin{array}{rrrr}\text { THOI } & \text { BW+JAM } & F & \text { F2 } \\ 11 & 0 & 0 & 0 \\ 10 & 5 & 0.020833 & 4.34028 \mathrm{E}-04 \\ 9.3 & 32 & 0.133333 & 0.017777778 \\ 9 & 33 & 0.1375 & 0.01890625 \\ 8 & 44 & 0.183333 & 0.033611111 \\ 7 & 83 & 0.345833 & 0.119600694 \\ 6 & 43 & 0.179166 & 0.032100694 \\ 5 & 0 & 0 & 0 \\ & 240 & 1 & 0.222430556\end{array}$

$\mathrm{H} t=0.777569$

$\mathrm{Hs}=0.757708$

Fst $=0.025542$ 


$\begin{array}{rrrrrrr}\text { THOI } & \text { BW } & \text { F BW } & \text { F2 BW } & \text { TRI } & \text { F TRI } & \text { F2 TRI } \\ 11 & 0 & 0 & 0 & 0 & 0 & 0 \\ 10 & 3 & 0.025 & 0.000625 & 2 & 0.016666667 & 2.77778 \mathrm{E}-04 \\ 9.3 & 28 & 0.233333 & 0.054444444 & 5 & 0.041666667 & 0.001736111 \\ 9 & 19 & 0.158333 & 0.025069444 & 20 & 0.166666667 & 0.027777778 \\ 8 & 17 & 0.141666 & 0.020069444 & 28 & 0.233333333 & 0.054444444 \\ 7 & 31 & 0.258333 & 0.066736111 & 41 & 0.341666667 & 0.116736111 \\ 6 & 22 & 0.183333 & 0.033611111 & 24 & 0.2 & 0.04 \\ 5 & 0 & 0 & 0 & 0 & 0 & 0 \\ & 120 & 1 & 0.200555556 & 120 & 1 & 0.240972222\end{array}$

THOI

$\begin{array}{rrrr}\text { Hs } & \text { BW } & \text { TRI } & \\ \text { Values } & & & \\ & 0.799444 & 0.759027 & \\ \text { THOI } & \text { BW+TRI } & \text { F } & \text { F2 } \\ 11 & 0 & 0 & 0 \\ 10 & 5 & 0.020833 & 4.34028 \mathrm{E}-04 \\ 9.3 & 33 & 0.1375 & 0.01890625 \\ 9 & 39 & 0.1625 & 0.02640625 \\ 8 & 45 & 0.1875 & 0.03515625 \\ 7 & 72 & 0.3 & 0.09 \\ 6 & 46 & 0.191666 & 0.036736111 \\ 5 & 0 & 0 & 0 \\ & 240 & 1 & 0.207638889\end{array}$

$\mathrm{H} t=0.792361$

$\mathrm{Hs}=0.779236$

Fst $=0.016564$ 


\begin{tabular}{|c|c|c|c|c|c|c|}
\hline THOI & $\mathrm{BB}$ & $\mathrm{F} B \mathrm{BB}$ & $\mathrm{F} 2 \mathrm{BB}$ & $\mathrm{BAH}$ & $\mathrm{F} \mathrm{BAH}$ & $\mathrm{F} 2 \mathrm{BAH}$ \\
\hline 11 & 0 & 0 & 0 & 0 & 0 & \\
\hline 10 & 0 & 0 & 0 & 2 & 0.016666667 & $2.77778 \mathrm{E}-04$ \\
\hline 9.3 & 9 & 0.075 & 0.005625 & 10 & 0.083333333 & 0.006944444 \\
\hline 9 & 18 & 0.15 & 0.0225 & 17 & 0.141666667 & 0.020069444 \\
\hline 8 & 27 & 0.225 & 0.050625 & 31 & 0.258333333 & 0.066736111 \\
\hline 7 & 47 & 0.391666 & 0.153402778 & 48 & 0.4 & 0.16 \\
\hline 6 & 19 & 0.158333 & 0.025069444 & 12 & 0.1 & 0.01 \\
\hline \multirow[t]{2}{*}{5} & 0 & 0 & 0 & 0 & 0 & \\
\hline & 120 & 1 & 0.257222222 & 120 & 1 & 0.26402777 \\
\hline
\end{tabular}

THOI

$\begin{array}{rrrr}\text { HsValues } & \text { BB } & \text { BAH } & \\ & 0.742777 & 0.735972 & \\ \text { THOI } & \text { BB+BAH } & \text { F } & \text { F2 } \\ 11 & 0 & 0 & 0 \\ 10 & 2 & 0.008333 & 6.94444 \mathrm{E}-05 \\ 9.3 & 19 & 0.079166 & 0.006267361 \\ 9 & 35 & 0.145833 & 0.021267361 \\ 8 & 58 & 0.241666 & 0.058402778 \\ 7 & 95 & 0.395833 & 0.156684028 \\ 6 & 31 & 0.129166 & 0.016684028 \\ 5 & 0 & 0 & 0 \\ & 240 & 1 & 0.259375\end{array}$

$\mathrm{H} t=0.740625$

$\mathrm{Hs}=0.739375$

Fst $=0.001687$ 


$\begin{array}{rrrrrrr}\text { THOI } & \text { BB } & \text { F BB } & \text { F2 BB } & \text { JAM } & \text { F JAM } & \text { F2 JAM } \\ 11 & 0 & 0 & 0 & 0 & 0 & 0 \\ 10 & 0 & 0 & 0 & 2 & 0.016666667 & 2.77778 \mathrm{E}-04 \\ 9.3 & 9 & 0.075 & 0.005625 & 4 & 0.033333333 & 0.001111111 \\ 9 & 18 & 0.15 & 0.0225 & 14 & 0.116666667 & 0.013611111 \\ 8 & 27 & 0.225 & 0.050625 & 27 & 0.225 & 0.050625 \\ 7 & 47 & 0.391666 & 0.153402778 & 52 & 0.433333333 & 0.187777778 \\ 6 & 19 & 0.158333 & 0.025069444 & 21 & 0.175 & 0.030625 \\ 5 & 0 & 0 & 0 & 0 & 0 & 0 \\ & 120 & 1 & 0.257222222 & 120 & 1 & 0.284027778\end{array}$

THOI

Hs
Values

$\begin{array}{lll}0.742777 & 0.715972\end{array}$

THOI BB+JAM F

11

10

9.3

20.008333

130.054166

$32 \quad 0.133333$

$\begin{array}{ll}54 & 0.225\end{array}$

$99 \quad 0.4125$

$40 \quad 0.166666$

6

5

240

1

$\mathrm{H} t=0.730659$

$\mathrm{Hs}=0.729375$

Fst $=0.001758$

$F 2$
0
$6.94444 \mathrm{E}-05$
0.002934028
0.017777778
0.050625
0.17015625
0.027777778
0
0.269340278

F2

$0.94444 \mathrm{E}-05$

0.017777778

0.17015625

0.269340278

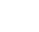




$\begin{array}{rrrrrrr}\text { THOI } & \text { BB } & \text { F BB } & \text { F2 BB } & \text { JAM } & \text { F JAM } & \text { F2 JAM } \\ 11 & 0 & 0 & 0 & 0 & 0 & 0 \\ 10 & 0 & 0 & 0 & 2 & 0.016666667 & 2.77778 \mathrm{E}-04 \\ 9.3 & 9 & 0.075 & 0.005625 & 4 & 0.033333333 & 0.001111111 \\ 9 & 18 & 0.15 & 0.0225 & 14 & 0.116666667 & 0.013611111 \\ 8 & 27 & 0.225 & 0.050625 & 27 & 0.225 & 0.050625 \\ 7 & 47 & 0.391666 & 0.153402778 & 52 & 0.43333333 & 0.187777778 \\ 6 & 19 & 0.158333 & 0.025069444 & 21 & 0.175 & 0.030625 \\ 5 & 0 & 0 & 0 & 0 & 0 & 0 \\ & 120 & 1 & 0.257222222 & 120 & 1 & 0.284027778\end{array}$

$\begin{array}{rrrr}\begin{array}{r}\text { THOI } \\ \text { Hs }\end{array} & \text { BB } & \text { JAM } & \\ \text { Values } & & & \\ & 0.742777 & 0.715972 & \\ \text { THOI } & & & \\ 11 & \text { BB+JAM } & F & \text { F2 } \\ 10 & 0 & 0 & 0 \\ 9.3 & 2 & 0.008333 & 6.94444 \mathrm{E}-05 \\ 9 & 13 & 0.054166 & 0.002934028 \\ 8 & 32 & 0.133333 & 0.017777778 \\ 7 & 54 & 0.225 & 0.050625 \\ 6 & 99 & 0.4125 & 0.17015625 \\ 5 & 40 & 0.166666 & 0.027777778 \\ & 0 & 0 & 0 \\ & 240 & 1 & 0.269340278\end{array}$

$\mathrm{H} t=0.730659$

$\mathrm{Hs}=0.729375$

Fst $=0.001758$ 


$\begin{array}{rrrrrrr}\text { THOI } & \text { BB } & \text { F BB } & \text { F2 BB } & \text { TRI } & \text { F TRI } & \text { F2 TRI } \\ 11 & 0 & 0 & 0 & 0 & 0 & 0 \\ 10 & 0 & 0 & 0 & 2 & 0.016666667 & 2.77778 E-04 \\ 9.3 & 9 & 0.075 & 0.005625 & 5 & 0.041666667 & 0.001736111 \\ 9 & 18 & 0.15 & 0.0225 & 20 & 0.166666667 & 0.027777778 \\ 8 & 27 & 0.225 & 0.050625 & 28 & 0.233333333 & 0.054444444 \\ 7 & 47 & 0.391666 & 0.153402778 & 41 & 0.341666667 & 0.116736111 \\ 6 & 19 & 0.158333 & 0.025069444 & 24 & 0.2 & 0.04 \\ 5 & 0 & 0 & 0 & 0 & 0 & 0 \\ & 120 & 1 & 0.257222222 & 120 & 1 & 0.240972222\end{array}$

THOI

$\begin{array}{rrr}\text { Hs } & \text { BB } & \text { TRI } \\ \text { Values } & & \\ & 0.742777 & 0.759027\end{array}$

$\begin{array}{rrrr}\text { THOI } & \text { BB+TRI } & F & \text { F2 } \\ 11 & 0 & 0 & 0 \\ 10 & 2 & 0.008333 & 6.94444 \mathrm{E}-05 \\ 9.3 & 14 & 0.058333 & 0.003402778 \\ 9 & 38 & 0.158333 & 0.025069444 \\ 8 & 55 & 0.229166 & 0.052517361 \\ 7 & 88 & 0.366666 & 0.134444444 \\ 6 & 43 & 0.179166 & 0.032100694 \\ 5 & 0 & 0 & 0 \\ & 240 & 1 & 0.247604167\end{array}$

$\mathrm{H} t=0.752395$

$\mathrm{Hs}=0.750902$

Fst $=0.001984$ 


$\begin{array}{rrrrrrr}\text { THOI } & \text { BAH } & \text { F BAH } & \text { F2 BAH } & \text { JAM } & \text { F JAM } & \text { F2 JAM } \\ 11 & 0 & 0 & 0 & 0 & 0 & 0 \\ 10 & 2 & 0.016666 & 2.77778 \mathrm{E}-04 & 2 & 0.016666667 & 2.77778 \mathrm{E}-04 \\ 9.3 & 10 & 0.083333 & 0.006944444 & 4 & 0.033333333 & 0.001111111 \\ 9 & 17 & 0.141666 & 0.020069444 & 14 & 0.116666667 & 0.013611111 \\ 8 & 31 & 0.258333 & 0.066736111 & 27 & 0.225 & 0.050625 \\ 7 & 48 & 0.4 & 0.16 & 52 & 0.433333333 & 0.187777778 \\ 6 & 12 & 0.1 & 0.01 & 21 & 0.175 & 0.030625 \\ 5 & 0 & 0 & 0 & 0 & 0 & 0 \\ & 120 & 1 & 0.264027778 & 120 & 1 & 0.284027778\end{array}$

THOI

$\begin{array}{rrrr}\text { Hs } & \text { BAH } & \text { JAM } & \\ \text { Values } & & & \\ & 0.735972 & 0.715972 & \\ \text { THOI } & \text { BAH+JAM } & \text { F } & \text { F2 } \\ 11 & 0 & 0 & 0 \\ 10 & 4 & 0.016666 & 2.77778 \mathrm{E}-04 \\ 9.3 & 14 & 0.058333 & 0.003402778 \\ 9 & 31 & 0.129166 & 0.016684028 \\ 8 & 58 & 0.241666 & 0.058402778 \\ 7 & 100 & 0.416666 & 0.173611111 \\ 6 & 33 & 0.1375 & 0.01890625 \\ 5 & 0 & 0 & 0 \\ & 240 & 1 & 0.271284722 \\ \text { Ht }= & 0.728715 & & \\ \text { Hs }= & 0.725972 & & \\ \text { Fst }= & 0.003764 & & \\ \end{array}$




$\begin{array}{rrrrrrr}\text { THOI } & \text { BAH } & \text { F BAH } & \text { F2 BAH } & \text { TRI } & \text { F TRI } & \text { F2 TRI } \\ 11 & 0 & 0 & 0 & 0 & 0 & 0 \\ 10 & 2 & 0.016666 & 2.77778 \mathrm{E}-04 & 2 & 0.016666667 & 2.77778 \mathrm{E}-04 \\ 9.3 & 10 & 0.083333 & 0.006944444 & 5 & 0.041666667 & 0.001736111 \\ 9 & 17 & 0.141666 & 0.020069444 & 20 & 0.166666667 & 0.027777778 \\ 8 & 31 & 0.258333 & 0.066736111 & 28 & 0.233333333 & 0.054444444 \\ 7 & 48 & 0.4 & 0.16 & 41 & 0.341666667 & 0.116736111 \\ 6 & 12 & 0.1 & 0.01 & 24 & 0.2 & 0.04 \\ 5 & 0 & 0 & 0 & 0 & 0 & 0 \\ & 120 & 1 & 0.264027778 & 120 & 1 & 0.240972222\end{array}$

\footnotetext{
THOI

\begin{tabular}{|c|c|c|}
\hline $\mathrm{Hs}$ & $\mathrm{BAH}$ & TRI \\
\hline & 0.735972 & 0.759027 \\
\hline
\end{tabular}
}

$\begin{array}{rrrr}\text { THOI } & \text { BAH+TRI } & \text { F } & \text { F2 } \\ 11 & 0 & 0 & 0 \\ 10 & 4 & 0.016666 & 2.77778 \mathrm{E}-04 \\ 9.3 & 15 & 0.0625 & 0.00390625 \\ 9 & 37 & 0.154166 & 0.023767361 \\ 8 & 59 & 0.245833 & 0.060434028 \\ 7 & 89 & 0.370833 & 0.137517361 \\ 6 & 36 & 0.15 & 0.0225 \\ 5 & 0 & 0 & 0 \\ & 240 & 1 & 0.248402778\end{array}$

$\mathrm{H} t=0.751597$

$\mathrm{Hs}=0.7475$

Fst $=0.005451$ 


$\begin{array}{rrrr}\text { THOI } & \text { JAM } & \text { F JAM } & \text { F2 JAM } \\ 11 & 0 & 0 & 0 \\ 10 & 2 & 0.016666 & 2.77778 \mathrm{E}-04 \\ 9.3 & 4 & 0.033333 & 0.001111111 \\ 9 & 14 & 0.116666 & 0.013611111 \\ 8 & 27 & 0.225 & 0.050625 \\ 7 & 52 & 0.433333 & 0.187777778 \\ 6 & 21 & 0.175 & 0.030625 \\ 5 & 0 & 0 & 0 \\ & 120 & 1 & 0.284027778\end{array}$

$\begin{array}{rrr}\text { TRI } & \text { F TRI } & \text { F2 TRI } \\ 0 & 0 & 0 \\ 2 & 0.016666667 & 2.77778 \mathrm{E}-04 \\ 5 & 0.041666667 & 0.001736111 \\ 20 & 0.166666667 & 0.027777778 \\ 28 & 0.233333333 & 0.054444444 \\ 41 & 0.341666667 & 0.116736111 \\ 24 & 0.2 & 0.04 \\ 0 & 0 & 0 \\ 120 & 1 & 0.240972222\end{array}$

THOI

$\begin{array}{rrrr}\text { Hs } & \text { JAM } & \text { TRI } \\ \text { Values } & & \\ & 0.715972 & 0.759027\end{array}$

$\begin{array}{rrrr}\text { THOI } & \text { JAM+TRI } & \text { F } & \text { F2 } \\ 11 & 0 & 0 & 0 \\ 10 & 4 & 0.016666 & 2.77778 \mathrm{E}-04 \\ 9.3 & 9 & 0.0375 & 0.00140625 \\ 9 & 34 & 0.141666 & 0.020069444 \\ 8 & 55 & 0.229166 & 0.052517361 \\ 7 & 93 & 0.3875 & 0.15015625 \\ 6 & 45 & 0.1875 & 0.03515625 \\ 5 & 0 & 0 & 0 \\ & 240 & 1 & 0.259583333\end{array}$

$\mathrm{H} t=0.740416$

$\mathrm{Hs}=0.7375$

Fst $=0.003939$ 
G Test Values for CSF

\begin{tabular}{|l|l|l|l|l|}
\hline & BB & BAH & JAM & TRI \\
\hline BW & $24.4116^{\star}$ & $16.9111^{\star}$ & $33.6854^{\star}$ & $30.3304^{\star}$ \\
\hline BB & & 12.6070 & 5.9669 & 6.2964 \\
\hline BAH & & & 11.7592 & 10.0759 \\
\hline JAM & & & & 6.0579 \\
\hline
\end{tabular}

$G$ Test Values for TPOX

\begin{tabular}{|l|l|l|l|l|}
\hline & BB & BAH & JAM & TRI \\
\hline BW & $16.3612^{\star}$ & $40.7965^{\star}$ & $23.7061^{\star}$ & $14.8656^{\star}$ \\
\hline BB & & 15.7348 & 10.8610 & 5.2652 \\
\hline BAH & & & 9.7282 & 11.8822 \\
\hline JAM & & & & 9.6518 \\
\hline
\end{tabular}

G Test Values for THO1

\begin{tabular}{|l|l|l|l|l|}
\hline & BB & BAH & JAM & TRI \\
\hline BW & $18.5581^{\star}$ & $19.5202^{\star}$ & $26.5668^{\star}$ & $20.4207^{\star}$ \\
\hline BB & & 3.9482 & 4.7756 & 4.25686 \\
\hline BAH & & & 5.7522 & 6.6130 \\
\hline JAM & & & & 2.6892 \\
\hline
\end{tabular}

TABLE 2 : Above tables give G-test values for all three loci and possible combinations. The 2-way $\mathrm{R} \times \mathrm{C}$ contingency table calculating the G-statistic was carried out with a program provided by G. Carmody (Ottawa, Canada).

* probability values less than 0.01 


\begin{tabular}{|l|l|l|l|l|}
\hline \multicolumn{5}{|c}{ Values for CSF } \\
\hline & BB & BAH & JAM & TRI \\
\hline BW & $29.5593^{\star}$ & $22.0087^{\star}$ & $42.7025^{\star}$ & $38.9094^{\star}$ \\
\hline BB & & 14.0636 & 6.0456 & 6.4802 \\
\hline BAH & & & 12.8414 & 11.0459 \\
\hline JAM & & & & 6.1724 \\
\hline
\end{tabular}

$\mathrm{X}^{2}$ Values for TPOX

\begin{tabular}{|l|l|l|l|l|}
\hline & BB & BAH & JAM & TRI \\
\hline BW & $21.3928^{\star}$ & $48.8640^{\star}$ & $27.8186^{\star}$ & $19.1355^{\star}$ \\
\hline BB & & 16.3862 & 11.4945 & 5.8191 \\
\hline BAH & & & 10.2998 & 12.0506 \\
\hline JAM & & & & 10.1708 \\
\hline
\end{tabular}

$\mathrm{X}^{2}$ Values FOR THO1

\begin{tabular}{|l|l|l|l|l|}
\hline & BB & BAH & JAM & TRI \\
\hline BW & $20.2422^{\star}$ & $20.0058^{\star}$ & $28.8975^{\star}$ & $22.0998^{\star}$ \\
\hline BB & & 4.7346 & 5.6001 & 5.0470 \\
\hline BAH & & & 5.8694 & 6.7239 \\
\hline JAM & & & & 2.6981 \\
\hline
\end{tabular}

TABLE 3: $\chi^{2}$ values for all loci with all possible population combinations.

* probability values less than 0.01 


\begin{tabular}{|c|c|c|}
\hline \multirow{2}{*}{ LOCI } & T-VALUE & CRITICAL T-VALUE \\
\hline CSF1PO & $7.40^{*}$ & \\
\hline TPOX & 1.75 & 2.306 \\
\hline THO1 & $3.40^{*}$ & 2.306 \\
\hline
\end{tabular}

TABLE 4: T-test values between Broward whites and African Descent population.* marks significant values. 


\begin{tabular}{|c|c|c|}
\hline LOCI & T-VALUE & CRITICAL T-VALUE \\
\hline CSF1PO & $-.2000^{*}$ & 3.182 \\
\hline TPOX & $-.3256^{*}$ & 3.182 \\
\hline THO1 & $-.5862^{*}$ & 3.182 \\
\hline
\end{tabular}

TABLE 5: T-values between Broward blacks and other African descent populations. * mark significant values. 